Purdue University Purdue e-Pubs

$1-31-2005$

\title{
Investigation of Heat Transfer in Rectangular Microchannels
}

Poh-Seng Lee

S V. Garimella

Purdue University, sureshg@purdue.edu

Dong Liu

Follow this and additional works at: http://docs.lib.purdue.edu/coolingpubs

Lee, Poh-Seng; Garimella, S V.; and Liu, Dong, "Investigation of Heat Transfer in Rectangular Microchannels" (2005). CTRC Research Publications. Paper 7.

http://dx.doi.org/10.1016/j.ijheatmasstransfer.2004.11.019

This document has been made available through Purdue e-Pubs, a service of the Purdue University Libraries. Please contact epubs@purdue.edu for additional information. 


\title{
Investigation of Convective Heat Transfer in Rectangular Microchannels ${ }^{\S}$
}

\author{
Poh-Seng Lee, Suresh V. Garimella ${ }^{\text {Il }}$ and Dong Liu \\ Cooling Technologies Research Center \\ School of Mechanical Engineering \\ Purdue University \\ West Lafayette, Indiana 47907-2088 USA
}

\begin{abstract}
An experimental investigation was conducted to explore the validity of classical correlations based on conventional-sized channels for predicting the thermal behavior in single-phase flow through rectangular microchannels. The microchannels considered ranged in width from $194 \mu \mathrm{m}$ to $534 \mu \mathrm{m}$, with the channel depth being nominally five times the width in each case. Each test piece was made of copper and contained ten microchannels in parallel. The experiments were conducted with deionized water, with the Reynolds number ranging from approximately 300 to 3500. Numerical predictions obtained based on a classical, continuum approach were found to be in good agreement with the experimental data (showing an average deviation of 5 percent), suggesting that a conventional analysis approach can be employed in predicting heat transfer behavior in microchannels of the dimensions considered in this study. However, the entrance and boundary conditions imposed in the experiment need to be carefully matched in the predictive approaches.
\end{abstract}

Keywords: Microchannel, electronics cooling, liquid cooling, high heat flux, heat sink

\footnotetext{
${ }^{\S}$ Submitted for publication in International Journal of Heat and Mass Transfer, March 2004, and in revised form, November 2004

II Author to whom correspondence should be addressed: 765-494-5621; 765-494-0539 (fax); sureshg@ecn.purdue.edu
} 


\section{NOMENCLATURE}
A convection heat transfer area (per channel), $\mathrm{m}^{2}$
b channel height, $\mu \mathrm{m}$
$\mathrm{c}_{\mathrm{p}} \quad$ specific heat, $\mathrm{kJ} / \mathrm{kg}^{\circ} \mathrm{C}$
$\mathrm{D}_{\mathrm{h}} \quad$ hydraulic diameter, $\mu \mathrm{m}$
f friction factor
h convective heat transfer coefficient, $\mathrm{W} / \mathrm{m}^{2 \circ} \mathrm{C}$
$\mathrm{k}$ thermal conductivity, $\mathrm{W} / \mathrm{m}^{\circ} \mathrm{C}$
L channel length
$\mathrm{L}_{\mathrm{ent}} \quad$ entrance length
$\mathrm{N}$ number of microchannels
$\mathrm{Nu} \quad$ Nusselt number
Pr Prandtl number
q heat transfer rate, $\mathrm{W}$
Q volumetric flow rate, $\mathrm{m}^{3} / \mathrm{s}$
Re Reynolds Number (based on tube diameter or channel hydraulic diameter)
t substrate thickness, $\mathrm{mm}$
T temperature, ${ }^{\circ} \mathrm{C}$
w channel width, $\mu \mathrm{m}$
$\mathrm{W}_{\mathrm{w}} \quad$ channel wall thickness, $\mu \mathrm{m}$
$\mathrm{x}^{+} \quad$ dimensionless hydrodynamic axial distance
X* dimensionless thermal axial distance

\section{Greek symbols}

$\alpha \quad$ channel aspect ratio

$\rho \quad$ density, $\mathrm{kg} / \mathrm{m}^{3}$ 


\begin{tabular}{ll}
\multicolumn{2}{l}{ Subscripts } \\
f & fluid \\
fd & fully developed flow \\
h & heater \\
hyd & hydrodynamic \\
i & inlet \\
o & outlet \\
t & thermal \\
x & local \\
w & wall
\end{tabular}

\section{INTRODUCTION}

Heat transfer in microchannels has been studied in a number of investigations, and has been compared and contrasted with the behavior at "conventional" (i.e., larger-sized) length scales. However, there have been wide discrepancies between different sets of published results. Measured heat transfer coefficients have either well exceeded [1], or fallen far below [2, 3], those predicted for conventional channels. The Reynolds number at which the thermal behavior indicates a transition from laminar to turbulent flow has also differed widely in these studies. Possible reasons advanced to account for the deviation from classical theory have included surface roughness [4], electrical double layer [5] and aspect ratio [6] effects. The capability of Navier-Stokes equations to adequately represent the flow and heat transfer behavior in microchannels has been called into question in some of these studies.

Tuckerman and Pease [7] first suggested the use of microchannels for high heat flux removal; this heat sink is simply a substrate with numerous small channels and fins arranged in parallel, such that heat is efficiently carried from the substrate into the coolant. Their study was conducted for water flowing under laminar conditions through microchannels machined in a silicon wafer. Heat fluxes as high as 790 $\mathrm{W} / \mathrm{cm}^{2}$ were achieved with the chip temperature maintained below $110^{\circ} \mathrm{C}$. Peng et al. [2, 8] 
experimentally investigated the flow and heat transfer characteristics of water flowing through rectangular stainless steel microchannels with hydraulic diameters of 133 to $367 \mu \mathrm{m}$ at channel aspect ratios of 0.33 to 1 . Their fluid flow results were found to deviate from the values predicted by classical correlations and the onset of transition was observed to occur at Reynolds numbers from 200 to 700 . These results were contradicted by the experiments of Xu et al. [9] who considered liquid flow in 30 to $344 \mu \mathrm{m}$ (hydraulic diameter) channels at Reynolds numbers of 20 to 4000. Their results showed that characteristics of flow in microchannels agree with conventional behavior predicted by Navier-Stokes equations. They suggested that deviations from classical behavior reported in earlier studies may have resulted from errors in the measurement of microchannel dimensions, rather than any microscale effects.

More recent studies have confirmed that the behavior of microchannels is quite similar to that of conventional channels. Liu and Garimella [10] showed that conventional correlations offer reliable predictions for the laminar flow characteristics in rectangular microchannels over a hydraulic diameter range of 244 to $974 \mu \mathrm{m}$. Judy et al. [11] made extensive frictional pressure drop measurements for Reynolds numbers of 8 to 2300 in 15 to $150 \mu \mathrm{m}$ diameter microtubes. They used three different fluids, two tube materials, and two different tube cross-section geometries. No significant deviation from macroscale flow theory was revealed from their measurements. They concluded that if any non-NavierStokes flow phenomena existed, their influence was masked by experimental uncertainty.

Popescu et al. [12] conducted heat transfer experiments under laminar flow conditions at Reynolds numbers of 300 to 900 using very shallow channels, which were $10 \mathrm{~mm}$ wide and 128 to 521 $\mu \mathrm{m}$ deep. Their results showed small to non-existent departure from macroscale predictions. Although deviations were observed for the smallest channel size studied, the paucity of data under these conditions precluded firm conclusions from being drawn. Harms et al. [13] studied convective heat transfer of water in rectangular microchannels of $251 \mu \mathrm{m}$ width and $1000 \mu \mathrm{m}$ depth. In the laminar regime of Reynolds number investigated, the measured local Nusselt numbers agreed well with classical developing-flow theory. Qu and Mudawar [14] performed experimental and numerical investigations of pressure drop and 
heat transfer characteristics of single-phase laminar flow in $231 \mu \mathrm{m}$ by $713 \mu \mathrm{m}$ channels. Good agreement was found between the measurements and numerical predictions, validating the use of conventional Navier-Stokes equations for microchannels.

Other studies have considered the turbulent regime. Adams et al. [15] investigated single-phase forced convection of water in circular microchannels of diameter 0.76 and $1.09 \mathrm{~mm}$. Their experimental Nusselt numbers were significantly higher than those predicted by traditional large-channel correlations, such as the Gnielinski [16] correlation. Adams et al. [17] extended this work to non-circular microchannels of larger hydraulic diameters, greater than $1.13 \mathrm{~mm}$. All their data for the larger diameters were well predicted by the Gnielinski [16] correlation, leading them to suggest a hydraulic diameter of approximately $1.2 \mathrm{~mm}$ as a lower limit for the applicability of standard turbulent single-phase Nusselttype correlations to non-circular channels.

Recent reviews of the state of the art $[18,19]$ indicate that before predictions of flow and heat transfer rates in microchannels can be made with confidence, careful experiments are needed to resolve the discrepancies in the literature and to provide practical information on the design of microchannel heat sinks.

The present work complements the detailed flow field and pressure drop measurements of Liu and Garimella [10]. A systematic investigation is conducted of single-phase heat transfer in microchannels of hydraulic diameters ranging from 318 to $903 \mu \mathrm{m}$, at flow Reynolds numbers of 300 to 3500. An important focus of this work is to examine the validity of conventional correlations and numerical analysis approaches in predicting the heat transfer behavior in microchannels, for correctly matched inlet and boundary conditions.

\section{EXPERIMENTAL SETUP AND PROCEDURES}

A schematic of the experimental facility used in this investigation, which was modified from that used for pressure drop measurements in [10], is shown in Fig. 1. Deionized water from a holding tank is 
driven through the flow loop using pressurized nitrogen gas. This approach was found to be preferable to the use of a pump, and provided smooth and steady flow over a wide range of flow rates. A needle valve downstream of the pressure tank allows fine adjustment of the flow rate from 0.1 to 2.2 liters/min, which corresponds to a Reynolds number range of 300 to 3500 . The limit on pressure head generated in the experiments precluded higher flow rates from being considered. The fluid then passes through a $7 \mu \mathrm{m}$ filter and a flowmeter before entering the microchannel test section. Heated water exits the test section and is collected. A differential pressure transducer with a carrier demodulator is used to measure the pressure drop across the test section.

Details of the microchannel test section are shown in Fig. 2. The test section consists of a copper test block, a clear acrylic lid, an insulating G10 bottom piece and fiberglass insulation. The heat sink was machined from a square block of copper of dimensions $25.4 \mathrm{~mm} \times 25.4 \mathrm{~mm} \times 70 \mathrm{~mm}$. The microchannels were cut into the top surface using a jeweler's saw on a CNC machine. Five such test pieces were fabricated with microchannels of different widths, all with a nominal aspect ratio of five. Table 1 lists the microchannel dimensions in each of the fabricated test pieces.

Holes were drilled into the bottom of the copper block to house four cartridge heaters that can provide a combined maximum power input of $800 \mathrm{~W}$. Four copper-constantan (Type-T) thermocouples made from 36-gauge wire were embedded in the copper test section at $6.35 \mathrm{~mm}$ axial intervals. The topmost thermocouple was at a distance of $3.18 \mathrm{~mm}$ from the base of the microchannels (distance 's' shown in Fig. 3). The temperature readings from these thermocouples are extrapolated to provide the average microchannel wall temperature. Type-T thermocouples were also located at the inlet and outlet of the test section as shown in Fig. 2 to measure the fluid temperatures at these locations. All thermocouples were read into a data acquisition system. The voltage input to the cartridge heaters was controlled by a DC power supply unit. The power supplied was calculated using the measured voltage and current (measured by means of a shunt resistor) supplied to the heaters.

The steady-state sensible heat gain by the coolant can be determined from an energy balance: 


$$
\mathrm{q}=\rho c_{\mathrm{p}} \mathrm{Q}\left(\mathrm{T}_{\mathrm{m}, \mathrm{o}}-\mathrm{T}_{\mathrm{m}, \mathrm{i}}\right)
$$

The volumetric flow rate $\mathrm{Q}$ is measured with a flowmeter calibrated using a digital scale and stopwatch. The inlet and outlet fluid temperatures $\left(\mathrm{T}_{\mathrm{m}, \mathrm{o}}\right.$ and $\left.\mathrm{T}_{\mathrm{m}, \mathrm{i}}\right)$ are obtained using the two thermocouples positioned immediately upstream and downstream of the microchannels, respectively. The density and specific heat are calculated based on the mean fluid temperature $\mathrm{T}_{\mathrm{m}}$ (average of the fluid inlet and outlet temperatures). In general, 85 to $90 \%$ of the power provided to the cartridge heaters was transferred to the water: for instance, out of the $325.2 \mathrm{~W}$ of power dissipated by the cartridge heaters in Test \#1 (at $\operatorname{Re}=$ 1596), 286.2 W was transferred to the coolant. Although the input heat flux can also be determined from the measured temperature gradient using the four thermocouples in the copper block, the associated measurement uncertainty can be as large as $15 \%$ due to heat losses along the sides of the copper block. Therefore, the effective average heat flux based on the base area $\left(q^{\prime \prime}=q / L^{2}\right)$ is instead calculated using the measured sensible heat gain using Eq. (1). An average heat flux at the base of q" $\approx 45 \mathrm{~W} / \mathrm{cm}^{2}$ is maintained in the experiments.

The average heat transfer coefficient is determined from:

$$
h=q /\left[N A\left(T_{w}-T_{m}\right)\right]
$$

in which $\mathrm{A}$ is the area available for convection per channel, $\mathrm{L}(\mathrm{w}+2 \mathrm{~b}), \mathrm{N}$ is the total number of channels, $\mathrm{T}_{\mathrm{w}}$ is the average temperature of the channel wall and $\mathrm{T}_{\mathrm{m}}$ is the mean fluid temperature. As direct measurements of the microchannel wall temperature were not available, it was determined by extrapolation from the closest imbedded thermocouple reading, i.e., $\mathrm{T}_{\mathrm{w}}=\mathrm{T}_{4}-\left(\mathrm{s} \mathrm{q} / / \mathrm{k}_{\mathrm{Cu}}\right)$, where the dimension $\mathrm{s}$ and temperatures $\mathrm{T}_{\mathrm{w}}$ and $\mathrm{T}_{4}$ are illustrated in Fig. 3. Due to the high thermal conductivity of copper, the uncertainty involved with such an estimation of the wall temperature is less than $1 \%$. The corresponding average Nusselt number is calculated as $\mathrm{Nu}=\mathrm{hD}_{\mathrm{h}} / \mathrm{k}_{\mathrm{f}}$, in which the thermal conductivity of water was evaluated at the mean fluid temperature, $\mathrm{T}_{\mathrm{m}}$.

A standard error analysis [20] revealed uncertainties in the reported Nusselt numbers in the range of 6 to $17 \%$. The uncertainties were greatest for a given microchannel test piece at the highest flow rates 
due to smaller increases in mean fluid temperature from inlet to outlet. The primary contributions to the uncertainty come from the measurement of wall and fluid temperatures $\left( \pm 0.3^{\circ} \mathrm{C}\right)$ and microchannel dimensions $( \pm 15 \mu \mathrm{m})$. Experiments conducted over a period of months showed excellent repeatability.

The following procedure was followed for the conduct of each test. The test piece to be investigated was first mounted onto the G10 and acrylic frame. A water-tight seal was effected using a silicone sealant between the mating surfaces. Once the test section was assembled, the valve from the compressed nitrogen cylinder was opened to provide the necessary pressure head in the pressure vessel to drive the coolant through the flow loop. The desired flow rate for each test run was set using the needle valve. After the flow rate stabilized, the heater power supply was switched on and maintained at the required level, and a steady state was usually reached in 30 to 45 minutes. Readings from all the thermocouples were stored using the data acquisition system throughout the duration of the experiment. Each steady-state temperature value was calculated as an average of 100 readings. The experiments were conducted over the nominal Reynolds number range of 300 to 3500 .

With water as the working fluid, the current tests fall either into a hydrodynamically developed but thermally developing (TD) or a simultaneously developing (SD) regime, using the criteria that $\mathrm{x}^{+}=$ $L /\left(D_{h} R e\right)$ and $x^{*}=L /\left(D_{h} R e P r\right)$ should take values greater than 0.05 for fully developed conditions to be achieved.

\section{NUMERICAL ANALYSIS}

Heat transfer results obtained in a number of experimental studies on microchannels have been compared in the literature [13, 22, 33] against the numerical results of Wibulswas [21], to assess the applicability of a conventional analysis. Simultaneously developing as well as thermally developing flows in channels of rectangular cross-section were considered in [21], both with T (constant wall temperature) and H1 (constant wall heat flux with circumferentially constant wall temperature) boundary conditions [28]. Nusselt numbers from this analysis were reported as functions of the channel aspect ratio 
and dimensionless axial position, as shown in Table 2. Later studies [13, 22] have used curve-fits to these numerical results for predictive purposes. The main limitation in the analysis of [21] was that the results covered only four particular aspect ratios $(\alpha=1,2,3$ and 4), and the computational resources available at the time of the work necessitated very coarse computational meshes. These limited results have been widely applied in the literature to other aspect ratios and to much smaller channel dimensions by extrapolation. With the availability of enhanced computational capabilities, however, more accurate simulations of fluid flow and heat transfer in microchannels of different dimensions and aspect ratios can readily be conducted, as is done in the present work.

In the present work, a numerical model was formulated to solve for the 3D conjugate heat transfer in the microchannel heat sink, accounting for both convection in the channel and conduction in the substrate. Simulations were performed for the specific test geometries considered in this study. The computational domain, chosen from symmetry considerations, is shown in Fig. 4(a); the top surface was adiabatic while the two sides were designated symmetric boundary conditions. A uniform heat flux was applied at the bottom surface, simulating the heat flow from the cartridge heaters. The substrate thickness included in the model was chosen (somewhat arbitrarily) to be $1.5 \mathrm{~mm}$, since the heat flux in the substrate can be expected to be relatively uniform due to its high thermal conductivity. At the inlet, a fully developed velocity profile was specified for thermally developing flow simulations, while a uniform inlet velocity profile was used for simultaneously developing flow simulations. An outflow boundary condition was specified at the exit in both cases. The coolant (water) was treated as being incompressible and Newtonian, with constant thermophysical properties over the range of temperatures considered (22 to $70^{\circ} \mathrm{C}$ ). Only flow rates in the laminar regime were considered. The commercial software package FLUENT [23] was used for the computations. The convective and conductive terms were discretized using first-order upwind and second-order central-difference schemes, respectively. The entire computational domain was discretized using a $50 \times 160 \times 100(x-y-z)$ grid. Simulations with different grids showed a satisfactory grid-independence for the results obtained with this mesh. For example, for 
the smallest microchannel $(\mathrm{w}=194 \mu \mathrm{m}, \mathrm{b}=884 \mu \mathrm{m})$, with $\mathrm{Re}=1100$, the average Nusselt number was predicted to be $8.82,9.05$, and 9.00 for mesh sizes of $40 \times 128 \times 80,50 \times 160 \times 100$ and $60 \times 192 \times 120$ respectively. The predicted average Nusselt number changed by $2.6 \%$ from the first to the second mesh, and only by $0.5 \%$ upon further refinement to the finest grid. Hence the intermediate $(50 \times 160 \times 100)$ grid was used in the fluid domain for the results presented in this work.

This comprehensive conjugate heat transfer model can be simplified by assuming different sets of thermal boundary conditions around the microchannel flow domain. While not all details of the real thermal situation are faithfully represented in these simplifications, such simplified approaches which omit a consideration of conduction in the substrate are more computationally economical and the results can also be generalized more readily to microchannels of different dimensions, de-coupled from the substrate conditions. Boundary conditions on the four microchannel walls could include $\mathrm{H} 2$ (uniform wall heat flux), $\mathrm{T}$ (uniform wall temperature) or H1 (axially uniform heat flux with circumferentially uniform temperature) conditions [28]. While the first two of these were straightforward to implement, the H1 boundary condition was achieved in the FLUENT [23] simulation by employing a thin and highly conductive wall, but with no axial conduction (henceforth referred to as the "thin wall" model).

Numerical simulations were performed under these simplifications for the microchannel geometries tested in the experiments, in addition to the comprehensive conjugate analysis. Figure 4(b) shows a schematic diagram of the microchannel cross-section considered in the simplified numerical models. Utilizing symmetry conditions, only a quarter of the domain was modeled. A uniform mesh was used along the channel width and height, while the mesh in the channel length direction had a successive ratio of 1.08. For the microchannels considered in this study, with a nominal aspect ratio of 5, a computational grid of $20 \times 50 \times 100$ cells was found to be adequate for the quarter domain shown in Fig. 4(b). Simulations with different grids showed a satisfactory grid-independence for the results obtained with this mesh. For example, for the smallest microchannel ( $w=194 \mu \mathrm{m}, \mathrm{b}=884 \mu \mathrm{m})$, with $\mathrm{Re}=1100$, the average Nusselt number was predicted to be $8.78,8.87$, and 8.97 for mesh sizes of $16 \times 40 \times 80,20 \times 50 \times 100$ and $24 \times$ 
$60 \times 120$, respectively. As the difference in Nusselt numbers between the two finer meshes was only $1.1 \%$, the $20 \times 50 \times 100$ mesh was considered sufficiently accurate for the present computations.

The numerical predictions for the average Nusselt number are illustrated in Fig. 5 for the smallest microchannel $(\mathrm{w}=194 \mu \mathrm{m})$ as a function of Reynolds number. The figure shows that the $3 \mathrm{D}$ conjugate analysis agrees quite well with the measured heat transfer results. Since the microchannel heat sink is made of copper, the temperature around the periphery of the channel is smeared, while considerable redistribution of heat flux occurs as the thermal boundary layer develops, as indicated from the 3D conjugate analysis results shown in Figs. 6 (a) and (b). This is reflected in the fact that results in Fig. 5 obtained using a uniform heat flux boundary condition deviate by a $12.4 \%$ standard deviation from the full conjugate analysis, compared to a smaller deviation of $7.1 \%$ for the uniform temperature boundary condition. Even so, the assumption of uniform wall temperature is not accurate enough. A variation in wall temperature can be observed in Fig. 6 (b) along the streamwise direction. In contrast to these two simplified boundary conditions, predictions from the thin-wall approximation are in excellent agreement with the $3 \mathrm{D}$ conjugate analysis, deviating by less than $1.3 \%$. The thin-wall boundary condition essentially combines the uniform temperature and uniform heat flux conditions, with circumferential temperature uniformity brought about by the high conductivity of the thin wall, and the thinness of the wall accommodating the heat flux redistribution. The thin-wall modeling approach is therefore recommended as the most appropriate of the simplified boundary conditions, when full conjugate analyses are not feasible.

In the following section, numerical results from the 3D conjugate analysis and the simplified thinwall analysis are presented and compared to experimental measurements. 


\section{RESULTS AND DISCUSSION}

\subsection{Alternative Prediction Approaches}

Commonly used heat transfer correlations $[24,25,26,27,28]$ for laminar and turbulent flows in channels are enumerated in Table 3; these correlations have been widely employed in the literature for comparison against experimental results for microchannels. The correlations in the table are categorized according to the state of development of the flow and thermal fields and boundary conditions. It may be noted that although correlating equations (4) to (12) in Table 3 were originally developed for circular tubes, they have often been used for non-circular tubes with substitution of the hydraulic diameter $\mathrm{D}_{\mathrm{h}}$.

Based on comparison with these conventional correlations, various conclusions have been drawn regarding their applicability to microchannel heat transfer $[1,12,13,14,15,29-37]$. Table 4 summarizes the conditions considered in these past microchannel studies, the conventional correlations against which results were compared, the conclusions that were drawn regarding applicability of conventional correlations, and any new correlations that were proposed. The disparity in conclusions regarding the applicability of conventional correlations to the prediction of single-phase microchannel heat transfer is evident from this table. This is in contrast to the success of conventional correlations in predicting pressure drop in microchannels as demonstrated in $[10,11]$. Most of the studies summarized in Table 4 indicate an under-prediction of the measured Nusselt numbers by conventional laminar correlations, while no consistent trend is observed for comparisons with correlations in the turbulent range. Reasons for this disparity include uncertainties in channel geometry and temperature measurement in the experiments, as well as a mismatch in the conditions for which the conventional correlations were proposed (circular tubes, different entrance and boundary conditions, etc.). It is critical, therefore, that appropriate correlations which faithfully represent the geometry as well as the thermal and inlet boundary conditions in the experiments be selected for comparison.

To examine this issue further, the hydrodynamic and thermal entrance lengths for the experimental conditions in past studies are shown in Table 5. Using $\mathrm{x}^{*} \approx 0.05$ as the thermal entrance length, all studies (except for [1], which is the only study in the table where the working fluid is a gas) are 
seen to be in a thermally developing state. In a majority of the studies $[13,29,30,33,36]$ in which comparisons were made to conventional laminar correlations, a good portion of the channel length is in a hydrodynamic entrance region, such that the flow in these studies is in a state of simultaneously developing laminar flow. The Sieder-Tate [25] and Stephan [26] correlations (Eqs. (4) and (6)) were proposed for simultaneously developing flow conditions, but for circular tubes, and do not account for aspect ratio effects in rectangular channels. Wu and Little [29] and Peng et al. [32] reached contradictory conclusions when comparing their respective experimental results with predictions from Eq.(4). The Hausen correlation (Eq.(7)) for thermally developing flow was used for comparison in [36], even though the experimental conditions represent simultaneously developing flow. The wide discrepancy among different studies on single-phase heat transfer in microchannels can be attributed at least in part to inappropriately chosen correlations for the comparison. It also reveals the difficulty in fully accounting for all relevant parameters in a single empirical correlation. On the other hand, as indicated in Table 4, numerical approaches $[12,14]$ have been more successful in matching experiments. In the following, numerical predictions from [21] and from the present work are compared to the experimental results obtained in the present work.

\section{2. Experimental Results and Comparison to Predictions}

The experimental results obtained in this work for the five test pieces are presented in terms of the Nusselt number variation as a function of Reynolds number. Figure 7 shows such a plot for the smallest microchannels tested $(\mathrm{w}=194 \mu \mathrm{m})$. In this and other figures for larger microchannels (Figs. 8 through 11), the Nusselt number increases with Reynolds number as expected. On the log-log scale used, the dependence is a straight line at the lower flow rates (laminar flow), increasing to a different slope at the higher flow rates. The change in slope at the higher flow rates is an indication that the flow is no longer laminar, but is in a transitional or turbulent flow regime.

Predictions from correlations for fully developed and developing laminar flows [24, 25, 26, 27 , 28] are compared to the experimental data in Fig. 7(a), and are seen to deviate significantly. Similar 
deviations were observed for the other four sets of experiments as well, but such comparisons are left out of Figs. 8 to 11 for clarity. The Nusselt numbers from the experiment are higher than predictions for both fully developed and developing conditions. The simultaneously developing correlations, Eqs. (4) and (6), perform somewhat better than the thermally developing correlations, Eqs. (7) and (8)

The experimental results in the laminar range are compared in Fig. 7(b) to results from [21] and to predictions from the present numerical analysis. The experimental results are seen to match the numerical predictions, with the match being particularly close with the present thin wall model results. Within the laminar range, the experimental measurements appear to agree best with thermally developing predictions over the range of Reynolds numbers examined, approaching the present simultaneously developing predictions with an increase in Reynolds number. For instance, at $\mathrm{Re}=300$, the flow can be assumed as hydrodynamically developed as evidenced by the small value of $\mathrm{L}_{\mathrm{ent}, \mathrm{h}} / \mathrm{L}=0.188$ in Table 5 . When Reynolds number increases to 1500 , simultaneously developing conditions must be assumed since the ratio of $\mathrm{L}_{\mathrm{ent}, \mathrm{h}} / \mathrm{L}=0.939$ implies that hydrodynamic entrance effects extend along the entire channel. The significant deviation of the simultaneously developing (SD) results from [21] may be attributed to the assumption in that work of negligible transverse velocity components relative to the axial velocity, throughout the channel.

It may be noted that the calculation of hydrodynamic entrance length above was based on a uniform inlet velocity profile. In microchannel heat sinks, the flow encounters abrupt contraction at the inlet and expansion at the outlet. For such conditions, Rohsenow et al. [38] suggested that the inlet condition should be assumed as hydrodynamically fully developed but thermally developing, due to wake effects at the abrupt entrance prior to the channel. This was verified for the present conditions using a computational analysis which included inlet and exit manifolds; the development length was found to be much shorter $\left(\mathrm{L}_{\mathrm{ent}, \mathrm{h}} \mathrm{L} \approx 0.04\right.$ for $\left.\mathrm{Re}=300\right)$ than that which would result from an assumption of uniform inlet velocity $\left(\mathrm{L}_{\mathrm{ent}, \mathrm{h}} / \mathrm{L}=0.188\right.$, as in Table 5). Thermally developing flow is thus the appropriate assumption for the experimental conditions of this study. 
Although the focus of the present work is on laminar flow, the experiments extend into the turbulent range as well, to a Reynolds number of 3500. Beyond a range of Reynolds number of approximately 1500 2000, the experimental results show a change in slope, reflecting a transition from laminar flow. As seen in Fig. 7(c), the experimental Nusselt numbers are generally higher in this turbulent region than predictions from correlations in $[15,16,28]$. Predictions from the Petukhov and Dittus-Boelter [25] correlations, on the other hand, are seen to lie above the experimental data, possibly because they were proposed for fully turbulent flow $(\operatorname{Re}>3000)$, while results obtained in the present study cover more of a transitional regime. However, even the Hausen correlation proposed for the transitional regime $(2200<\operatorname{Re}<10000)$ [28] does not provide satisfactory predictions. It may be noted that entrance length effects are not accounted for in any of the turbulent flow correlations; even though entrance length effects are less important in turbulent flow, this may be a contributing factor to the observed discrepancies. The slope of variation of the Nusselt number with Reynolds number is, however, consistent with the predicted slopes from the Dittus-Boelter and Gnielinski correlations. Additional results in the turbulent region are needed to address this question further, and to identify predictive correlations suitable to this regime.

In Figs. 8 through 11, results are shown for the other four sets of microchannels tested, and are seen to be consistent with the observations made for the smallest microchannels in Fig. 7. Comparisons to the thermally developing predictions from [21] and from the present computations (both 3D conjugate and thin wall analyses) are included in the figures. In general, the experimental data are seen to agree with the thermally developing predictions at Reynolds numbers in the laminar range. The average deviation between the experiments and the computational results for the thermally developing state for all five test geometries is 5.5\% for results from [21] and 5.2\% for the present results, as detailed in Table 6 . This good agreement between experimental and simulation results suggests that a conventional computational analysis approach can adequately predict the heat transfer behavior in microchannels of the dimensions considered here. Deviations between the predictions and experiment are attributable mainly to experimental uncertainties. The results also confirm that the simplified numerical model with the thin 
wall approximation can be used as a computationally economical alternative to a full $3 \mathrm{D}$ conjugate analysis.

Figure 12 shows a comparison of the experimental convective heat transfer coefficients obtained for all five test pieces in the laminar regime. It shows clearly that the heat transfer coefficient initially decreases sharply as the dimensionless thermal axial distance, $x^{*}$, increases. The higher heat transfer coefficients at low $\mathrm{x}^{*}$ are caused by the thinner boundary layers in the developing region at high Reynolds numbers. In addition, Figure 12 illustrates clearly the significant enhancements in heat transfer that can be obtained by decreasing the size of a microchannel. For instance, the heat transfer coefficients for the smallest microchannel $(\mathrm{w}=194 \mu \mathrm{m})$ are almost three times the values for the largest microchannel $(\mathrm{w}=$ $534 \mu \mathrm{m})$ over the overlapping $\mathrm{x}^{*}$ range in the figure.

\section{CONCLUSIONS}

Heat transfer in microchannels of different sizes (with hydraulic diameters of 318 to $903 \mu \mathrm{m}$ ) was experimentally investigated over a range of flow rates. Single-phase flows in the thermally developing laminar regimes were considered. The heat transfer coefficient increased with decreasing channel size at a given flow rate. The experimental results were compared against conventional correlations to evaluate their applicability in predicting microchannel heat transfer. The wide disparities revealed that the mismatch in the boundary and inlet conditions between the microchannel experiments and the conventional correlations precluded their use for predictions. Numerical simulations were carried out for developing flows in rectangular channels based on a conventional Navier-Stokes analysis, using both a full 3-D conjugate approach and a simplified thin wall model. The numerical results were found to be in good agreement with the experimental data, suggesting that such approaches, when coupled with carefully matched entrance and boundary conditions, can be employed with confidence for predicting heat transfer behavior in microchannels in the dimensional range considered here. The results also confirm that the simplified thin wall analysis can be used as a computationally economical alternative to a full 3D 
conjugate analysis. In the transitional and turbulent regimes, improved correlations are needed to account for the developing conditions.

\section{Acknowledgement}

The authors acknowledge the financial support from members of the Cooling Technologies Research Center (www.ecn.purdue.edu/CTRC), a National Science Foundation Industry/University Cooperative Research Center at Purdue University.

\section{REFERENCES}

[1] Choi, S. B., Barron, R. F., and Warrington, R. O., 1991, "Fluid flow and heat transfer in microtubes," Micromechanical Sensors, Actuators and Systems, ASME DSC-Vol. 32, pp. 123-134.

[2] Peng, X. F., Peterson, G. P. and Wang, B. X., 1994, "Heat transfer characteristics of water flowing through microchannels," Exp. Heat Transfer, Vol. 7, pp. 265-283.

[3] Peng, X. F. and Peterson, G. P., 1996, "Convective heat transfer and flow friction for water flow in microchannel structures," Int. J. Heat Mass Transfer, Vol. 39, pp. 2599-2608.

[4] Mala, G. M. and Li, M., 1999, "Flow characteristics of water in microtubes," Int. J. Heat Fluid Flow, Vol. 20, pp. 142-148.

[5] Mala, G. M., Li, D. and Dale, J. D., 1997, "Heat transfer and fluid flow in microchannels," Int. J. Heat Mass Transfer, Vol. 40, pp. 3079-3088.

[6] Papautsky, I., Gale, B. K., Mohanty, S., Ameel, T.A. and Frazier, A. B., 2000, "Effects of rectangular microchannel aspect ratio on laminar friction constant," unpublished, from authors' website. [7] Tuckerman, D. B. and Pease, R. F. W., 1981, "High-performance heat sinking for VLSI," IEEE Electron Device Letters, Vol. 2, pp. 126-129.

[8] Peng, X. F., Peterson, G. P., and Wang, B. X., 1994, "Frictional flow characteristics of water flowing through microchannels," Exp. Heat Transfer, Vol. 7, pp. 249-264. 
[9] Xu B., Ooi, K. T., Wong, N. T. and Choi, W. K., 2000, "Experimental investigation of flow friction for liquid flow in microchannels," Int. Comm. Heat Mass Transfer, Vol. 27, pp. 1165-1176. [10] Liu, D. and Garimella, S. V., 2004, "Investigation of liquid flow in microchannels," AIAA J. Thermophys. Heat Transfer, Vol. 18, pp. 65-72.

[11] Judy, J., Maynes, D. and Webb, B. W., 2002, "Characterization of frictional pressure drop for liquid flows through microchannels," Int. J. Heat Mass Transfer, Vol. 45, pp. 3477-3489.

[12] Popescu, A., Welty, J. R., Pfund, D. and Rector, D., 2002, “Thermal measurements in rectangular microchannels," Procs. IMECE2002, IMECE2002-32442.

[13] Harms, T. M., Kazmierczak, M. J. and Gerner, F. M., 1999, "Developing convective heat transfer in deep rectangular microchannels," Int. J. Heat Fluid Flow, Vol. 20, pp. 149-157.

[14] Qu, W. and Mudawar, I., 2002, "Experimental and numerical study of pressure drop and heat transfer in a single-phase micro-channel heat sink," Int. J. Heat Mass Transfer, Vol. 45, pp. 2549-2565.

[15] Adams, T. M., Abdel-Khalik, S. I., Jeter, S. M. and Qureshi, Z. H., 1998, “An experimental investigation of single-phase forced convection in microchannels," Int. J. Heat Mass Transfer, Vol. 41, pp. 851-857.

[16] Gnielinski, V., 1976, "New equations for heat and mass transfer in turbulent pipe and channel flow," Int. Chem. Eng., Vol. 16, pp. 359-368.

[17] Adams, T. M., Dowling, M. F., Abdel-Khalik, S. I. and Jeter, S. M., 1999, “Applicability of traditional turbulent single-phase forced convection correlations to non-circular microchannels," Int. J. Heat Mass Transfer, Vol. 42, pp. 4411-4415.

[18] Sobhan, C. B. and Garimella, S. V, 2001, “A comparative analysis of studies on heat transfer and fluid flow in microchannels," Microscale Thermophys. Eng., Vol. 5, pp. 293-311.

[19] Garimella, S. V. and Sobhan, C. B., 2003, “Transport in microchannels - A critical review," Ann. Rev. Heat Transfer, Vol. 13, Chapter 1, pp. 1-50.

[20] Taylor J. R., 1997, An Introduction to Error Analysis, University Science Books. 
[21] Wibulswas, P., 1966, Laminar Flow Heat Transfer in Non-Circular Ducts, Ph.D Thesis, University College, London.

[22] Phillips, R. J., 1987, Microchannel Heat Sinks, Ph.D. Thesis, Massachusetts Institute of Technology.

[23] FLUENT 6 User's Guide, Lebanon, NH, Fluent Inc, 2000.

[24] Kays, W. M. and Crawford, M. E., 1980, Convective Heat and Mass Transfer, McGraw Hill, New York.

[25] Incropera, F. P. and DeWitt, D. P., 1996, Fundamentals of Heat and Mass Transfer, John Wiley and Sons, New York.

[26] Stephan, K. and Preußer, P., 1979, "Wärmeübergang und maximale Wärmestromdichte beim Behältersieden binärer und ternärer Flüssigkeitsgemische,” Chem.-Ing.-Tech.,Vol. 51, pp. 37.

[27] Shah, R. K. and London, A. L., 1978, "Laminar flow forced convection in ducts," Supplement 1, Adv. Heat Transfer.

[28] Kakac, S., Shah, R. K. and Aung, W., 1987, Handbook of Single-Phase Convective Heat Transfer, John Wiley and Sons, New York.

[29] Wu, P. and Little, W. A., 1983, "Measurement of friction factors for the flow of gases in very fine channels used for microminiature refrigerators," Cryogenics, Vol. 24, pp. 273-277.

[30] Rahman, M. M. and Gui, F., 1993, "Experimental measurements of fluid flow and heat transfer in microchannel cooling passages in a chip substrate," ASME EEP, Vol. 4, pp. 685-692.

[31] Yu, D., Warrington, R., Barron, R. and Ameel, T., 1995, “An experimental and theoretical investigation of fluid flow and heat transfer in microtubes," Procs. ASME/JSME Thermal Eng. Joint Conference, pp. 523-530.

[32] Peng, X. F. and Peterson, G. P., 1996, “Convective heat transfer and flow friction for water flow in microchannel structures," Int. J. Heat Mass Transfer, Vol. 39, pp. 2599-2608. 
[33] Ravigururajan, T. S. and Drost, M. K., 1999, "Single-phase flow thermal performance characteristics of a parallel microchannel heat exchanger," Enhanced Heat Transfer, Vol. 6, pp. 383-393. [34] Qu, W., Mala, G. M. and Li, D. Q., 2000, "Heat transfer for water flow in trapezoidal silicon microchannels," Int. J. Heat Mass Transfer, Vol. 43, pp. 3925-3936.

[35] Celata, G. P., Cumo, M., Guglielmi, M. and Zummo, G. 2002, "Experimental investigation of hydraulic and single phase heat transfer in $0.130 \mathrm{~mm}$ capillary tube," Microscale Thermophys. Eng., Vol. 6, pp. 85-97.

[36] Bucci, A., Celata, G. P., Cumo, M., Serra, E. and Zummo, G., 2003, "Water single-phase fluid flow and heat transfer in capillary tubes," Procs. $1^{\text {st }}$ Int. Conf. on Microchannels and Minichannels, ICMM2003-1037, April 24-25, Rochester, New York.

[37] Owhaib, W. and Palm, B., 2004, "Experimental investigation of single-phase convective heat transfer in circular microchannels," Exp. Thermal Fluid Sci., Vol. 28, pp. 105-110.

[38] Rohsenow, W. M., Hartnett, J. P., and Ganic, E. N., 1985, Handbook of Heat Transfer Applications, McGraw-Hill, New York. 


\section{LIST OF TABLES}

Table 1. Test matrix.

Table 2. Nusselt numbers in thermally developing laminar flow in rectangular channels at a constant heat flux [21, 22].

Table 3. Conventional correlations from the literature for the prediction of channel heat transfer.

Table 4. Conclusions in the literature regarding the validity of conventional correlations in predicting microchannel heat transfer.

Table 5. Assessment of entrance lengths in experimental studies of microchannels.

Table 6. Difference between experimental results and numerical predictions (H1, thermally developing conditions).

\section{LIST OF FIGURE CAPTIONS}

Fig. 1. Schematic of the experimental apparatus.

Fig. 2. Detailed view of the test section: (a) Side view (not to scale), and (b) Top view (to scale).

Fig. 3. Cross-section of the microchannel test piece (not to scale).

Fig. 4. Microchannel domains considered for (a) comprehensive 3-D conjugate analysis, and (b) simplified analyses.

Fig. 5. Comparison of the average Nusselt numbers obtained from different numerical analyses for the $194 \mu \mathrm{m}$ wide microchannels.

Fig. 6. Local profile of (a) temperature and (b) heat flux, on the channel side wall for the $194 \mu \mathrm{m}$ wide microchannels at a Reynolds number of 1100 .

Fig. 7. Nusselt numbers for the $194 \mu \mathrm{m}$ wide microchannels. Experimental data compared against: (a) correlations for laminar flow (SD - simultaneously developing, TD - thermally developing); (b) numerical predictions for laminar flow; and (c) correlations for turbulent flow.

Fig. 8. Nusselt numbers for the $229 \mu \mathrm{m}$ wide microchannels.

Fig. 9. Nusselt numbers for the $300 \mu \mathrm{m}$ wide microchannels.

Fig. 10. Nusselt numbers for the $339 \mu$ m wide microchannels.

Fig. 11. Nusselt numbers for the $534 \mu \mathrm{m}$ wide microchannels.

Fig. 12. Dependence of heat transfer coefficient on Reynolds numbers (in terms of dimensionless thermal axial distance $\mathrm{x}^{*}$ ) for channels of different hydraulic diameters. The dashed lines are trend line fits to the experimental data. 
Table 1. Test matrix.

\begin{tabular}{|c|c|c|c|c|c|c|}
\hline Test \# & $\begin{array}{c}\text { \# of } \\
\text { Channels }\end{array}$ & $\mathbf{W}(\boldsymbol{\mu m})$ & $\mathbf{b}(\boldsymbol{\mu m})$ & $\mathbf{L}(\mathbf{m m})$ & $\mathbf{D}_{\mathbf{h}}(\boldsymbol{\mu m})$ & $\boldsymbol{\alpha}(=\mathbf{b} / \mathbf{w})$ \\
\hline 1 & 10 & 194 & 884 & 25.4 & 318 & 4.56 \\
\hline 2 & 10 & 229 & 1250 & 25.4 & 387 & 5.46 \\
\hline 3 & 10 & 300 & 1520 & 25.4 & 501 & 5.07 \\
\hline 4 & 10 & 339 & 1895 & 25.4 & 575 & 5.59 \\
\hline 5 & 10 & 534 & 2910 & 25.4 & 903 & 5.45 \\
\hline
\end{tabular}


Table 2. Nusselt numbers in thermally developing laminar flow in rectangular channels at a constant heat flux [21, 22].

\begin{tabular}{|c|c|c|c|c|c|c|}
\hline \multirow{2}{*}{$\mathbf{x}^{\star}$} & \multicolumn{6}{|c|}{$\mathbf{N u}_{\mathbf{x}}$} \\
\cline { 2 - 7 } & $\alpha \leq 0.1$ & 1.0 & 2.0 & 3.0 & 4.0 & $\geq 10.0$ \\
\hline 0.0001 & 31.6 & 25.2 & 23.7 & 27 & 26.7 & 31.4 \\
\hline 0.0025 & 11.2 & 8.9 & 9.2 & 9.9 & 10.4 & 11.9 \\
\hline 0.005 & 9 & 7.1 & 7.46 & 8.02 & 8.44 & 10 \\
\hline 0.00556 & 8.8 & 6.86 & 7.23 & 7.76 & 8.18 & 9.8 \\
\hline 0.00625 & 8.5 & 6.6 & 6.96 & 7.5 & 7.92 & 9.5 \\
\hline 0.00714 & 8.2 & 6.32 & 6.68 & 7.22 & 7.63 & 9.3 \\
\hline 0.00833 & 7.9 & 6.02 & 6.37 & 6.92 & 7.32 & 9.1 \\
\hline 0.01 & 7.49 & 5.69 & 6.05 & 6.57 & 7 & 8.8 \\
\hline 0.0125 & 7.2 & 5.33 & 5.7 & 6.21 & 6.63 & 8.6 \\
\hline 0.0167 & 6.7 & 4.91 & 5.28 & 5.82 & 6.26 & 8.5 \\
\hline 0.025 & 6.2 & 4.45 & 4.84 & 5.39 & 5.87 & 8.4 \\
\hline 0.033 & 5.9 & 4.18 & 4.61 & 5.17 & 5.77 & 8.3 \\
\hline 0.05 & 5.55 & 3.91 & 4.38 & 5 & 5.62 & 8.25 \\
\hline 0.1 & 5.4 & 3.71 & 4.22 & 4.85 & 5.45 & 8.24 \\
\hline 1 & 5.38 & 3.6 & 4.11 & 4.77 & 5.35 & 8.23 \\
\hline
\end{tabular}


Table 3. Conventional correlations from the literature for the prediction of channel heat transfer.

\begin{tabular}{|c|c|c|c|c|c|}
\hline \multirow[t]{2}{*}{ Reference } & \multicolumn{2}{|l|}{ Correlation } & \multicolumn{2}{|r|}{ Conditions } & \multirow{2}{*}{$\begin{array}{l}\text { Range of } \\
\text { validity }\end{array}$} \\
\hline & & & Geometry & Flow regime & \\
\hline $\begin{array}{l}\text { Kays and Crawford } \\
\text { [24] }\end{array}$ & $N u_{f d}=8.235\left(1-1.883 / \alpha+3.767 / \alpha^{2}-5.814 / \alpha^{3}+5.361 / \alpha^{4}-2 / \alpha^{5}\right)$ & (3) & Rectangular & Fully developed & $\mathrm{Re}<2200$ \\
\hline $\begin{array}{l}\text { Incropera and DeWitt } \\
\text { [25] }\end{array}$ & Sieder-Tate correlation $N u=1.86(\operatorname{Re} \operatorname{Pr} D / L)^{1 / 3}\left(\frac{\mu_{f}}{\mu_{w}}\right)^{0.14}$ & (4) & Circular & Simultaneously developing & $\operatorname{Re}<2200$ \\
\hline \multirow{2}{*}{$\begin{array}{l}\text { Stephan and Preußer } \\
\text { [26] }\end{array}$} & Stephan correlation $N u=3.657+\frac{0.0677(\operatorname{Re} \operatorname{Pr} D / L)^{1.33}}{2}$ & \multirow[t]{2}{*}{ (5) } & \multirow[t]{2}{*}{ Circular } & \multirow{2}{*}{$\begin{array}{l}\text { Simultaneously developing } \\
\text { (constant wall temperature) }\end{array}$} & $0.7<\operatorname{Pr}<7$ \\
\hline & $N u=5.05 /+\frac{1+0.1 \operatorname{Pr}(\operatorname{Re} D / L)^{0.3}}{1+1}$ & & & & $\begin{array}{l}\text { Re } \operatorname{Pr} D / L<33 \\
\text { for } \operatorname{Pr}>7\end{array}$ \\
\hline \multirow{2}{*}{$\begin{array}{l}\text { Stephan and Preußer } \\
\text { [26] }\end{array}$} & \multirow{2}{*}{ Stephan correlation $N u=4.364+\frac{0.086(\operatorname{Re} \operatorname{Pr} D / L)^{1.33}}{1+01 \operatorname{Pr}(\operatorname{Pe} D / L)^{0.83}}$} & \multirow[t]{2}{*}{$(6)$} & \multirow[t]{2}{*}{ Circular } & \multirow{2}{*}{$\begin{array}{l}\text { Simultaneously developing } \\
\text { (constant wall heat flux) }\end{array}$} & $0.7<\operatorname{Pr}<7$ \\
\hline & & & & & $\begin{array}{l}\operatorname{Re} \operatorname{Pr} D / L<33 \\
\text { for } \operatorname{Pr}>7\end{array}$ \\
\hline \multirow{2}{*}{$\begin{array}{l}\text { Incropera and DeWitt } \\
\text { [25] }\end{array}$} & \multirow{2}{*}{\multicolumn{2}{|c|}{ Hausen correlation $N u=3.66+\frac{0.19(\operatorname{Re} \operatorname{Pr} D / L)^{0.8}}{17)^{0.467}}$}} & \multirow[t]{2}{*}{ Circular } & \multirow{2}{*}{$\begin{array}{l}\text { Thermally developing } \\
\text { laminar } \\
\text { (constant wall temperature) }\end{array}$} & \multirow[t]{2}{*}{$\operatorname{Re}<2200$} \\
\hline & & & & & \\
\hline \multirow[t]{2}{*}{ Shah and London [27] } & $N u=\left\{1.953\left(\operatorname{Re} \operatorname{Pr} \frac{D}{L}\right)^{1 / 3} \quad\left(\operatorname{Re} \operatorname{Pr} \frac{D}{L}\right) \geq 33.3\right.$ & \multirow[t]{2}{*}{ (8) } & \multirow[t]{2}{*}{ Circular } & \multirow[t]{2}{*}{$\begin{array}{l}\text { Thermally developing } \\
\text { laminar } \\
\text { (constant wall heat flux) }\end{array}$} & - \\
\hline & $4.364+0.0722 \operatorname{Re} \operatorname{Pr} \frac{D}{L} \quad\left(\operatorname{Re} \operatorname{Pr} \frac{D}{L}\right)<33.3$ & & & & \\
\hline Kakac et al. [28] & Hausen correlation $N u=0.116\left(\operatorname{Re}^{2 / 3}-125\right) \operatorname{Pr}^{1 / 3}\left[1+(D / L)^{2 / 3}\right]\left(\frac{\mu_{f}}{\mu_{w}}\right)^{0.14}$ & (9) & Circular & Transitional & $\begin{array}{l}2200<\operatorname{Re}< \\
10000\end{array}$ \\
\hline $\begin{array}{l}\text { Incropera and DeWitt } \\
\text { [25] }\end{array}$ & Dittus-Boelter correlation $N u=0.023 \operatorname{Re}^{0.8} \operatorname{Pr}^{1 / 3}$ & $(10)$ & Circular & Fully developed turbulent & $\operatorname{Re}>10000$ \\
\hline \multirow{2}{*}{$\begin{array}{l}\text { Incropera and DeWitt } \\
\text { [25] }\end{array}$} & \multirow{2}{*}{ Petukhov correlation $N u=\frac{(f / 8) \operatorname{Re} \operatorname{Pr}}{K+12.7(f / 8)^{1 / 2}\left(\operatorname{Pr}^{2 / 3}-1\right)}$} & \multirow[t]{4}{*}{$(11)$} & \multirow[t]{2}{*}{ Circular } & \multirow[t]{2}{*}{ Fully developed turbulent } & \multirow[t]{4}{*}{$\operatorname{Re}>10000$} \\
\hline & & & & & \\
\hline \multirow{4}{*}{ Gnielinski [16] } & \multirow{2}{*}{$K=1.07+\frac{900}{\operatorname{Re}}-\frac{0.63}{1+10 \operatorname{Pr}}$} & & & & \\
\hline & & & Circular & & \\
\hline & Gnielinski correlation $N u=\frac{(f / 8)(\mathrm{Re}-1000) \mathrm{Pr}}{1+12.7(f / 8)^{1 / 2}\left(\operatorname{Pr}^{2 / 3}-1\right)}$ & (12) & circular & developed turbulent & $\begin{array}{l}3000<\operatorname{Re} \\
<5 \times 10^{6}\end{array}$ \\
\hline & $f=\frac{1}{(1.82 \ln (\operatorname{Re})-1.64)^{2}}$ & & & & \\
\hline
\end{tabular}


Table 4. Conclusions in the literature regarding the validity of conventional correlations in predicting microchannel heat transfer.

\begin{tabular}{|c|c|c|c|c|}
\hline Reference & Parameters & $\begin{array}{c}\text { Conclusions on Validity of } \\
\text { Conventional Theory }\end{array}$ & $\begin{array}{c}\text { Conventional Correlations used in } \\
\text { Comparisons }\end{array}$ & Proposed New Correlation \\
\hline Wu and Little [29] & $\begin{array}{l}\mathrm{w}=89-92 \mu \mathrm{m} \\
\mathrm{b}=493-572 \mu \mathrm{m} \\
\mathrm{L}=28,30 \mathrm{~mm} \\
\operatorname{Re}=400-20000\end{array}$ & $\begin{array}{l}\text { Measured Nusselt numbers higher than } \\
\text { conventional correlations for both laminar } \\
\text { and turbulent flows }\end{array}$ & $\begin{array}{l}\text { Laminar flow }(\mathrm{Re}<2200) \text { : Eq. }(4) \\
\text { Transitional regime }(2200<\mathrm{Re}<10000) \text { : } \\
\text { Eq. (9) } \\
\text { Fully developed turbulent flow } \\
(\mathrm{Re}>10000) \text { : Eq. (10) }\end{array}$ & $\begin{array}{l}N u=0.00222 R \mathrm{e}^{1.09} \operatorname{Pr}^{0.4}(13) \\
(\operatorname{Re}>3000)\end{array}$ \\
\hline Choi et al. [1] & $\begin{array}{l}D=3-81.2 \mu \mathrm{m} \\
L=24-52 \mathrm{~mm} \\
R e=20-25000\end{array}$ & $\begin{array}{l}\text { Measured Nusselt numbers higher than } \\
\text { correlations for turbulent flow; exhibit Re- } \\
\text { dependence for laminar flow. }\end{array}$ & $\begin{array}{l}\text { No comparison to conventional laminar } \\
\text { flow correlation. } \\
\text { Turbulent flow: Eq. (10) }\end{array}$ & $\begin{array}{l}N u=0.000972 \operatorname{Re}^{1.17} \operatorname{Pr}^{1 / 3}(14) \\
(\operatorname{Re}<2000) \\
N u=3.82 \times 10^{-6} \operatorname{Re}^{1.96} \operatorname{Pr}^{1 / 3}(15) \\
(2500<\operatorname{Re}<20000)\end{array}$ \\
\hline $\begin{array}{l}\text { Rahman and Gui } \\
\text { [30] }\end{array}$ & $\begin{array}{l}w=176-325 \mu \mathrm{m} \\
b=1 \mathrm{~mm} \\
L=48 \mathrm{~mm} \\
\operatorname{Re}=300-3500\end{array}$ & $\begin{array}{l}\text { Measured Nusselt numbers higher than } \\
\text { analytical prediction for developing } \\
\text { laminar flow, but lower for turbulent flow. }\end{array}$ & $\begin{array}{l}\text { No equations provided, but authors refer } \\
\text { to [37] in which results from [21] appear } \\
\text { for laminar flow. }\end{array}$ & ( \\
\hline Yu et al. [31] & $\begin{array}{l}D=19-102 \mu \mathrm{m} \\
L=24-52 \mathrm{~mm} \\
\operatorname{Re}=2500-20000\end{array}$ & $\begin{array}{l}\text { Measured Nusselt numbers higher than } \\
\text { correlation for turbulent flow. }\end{array}$ & Turbulent flow: Eq. (10) & $\begin{array}{l}N u=0.007 \operatorname{Re}^{1.2} \operatorname{Pr}^{0.2}(16) \\
(6000<\operatorname{Re}<20000)\end{array}$ \\
\hline Peng et al. [32] & $\begin{array}{l}\mathrm{w}=100-300 \mu \mathrm{m} \\
\mathrm{b}=200-400 \mu \mathrm{m} \\
\mathrm{L}=50 \mathrm{~mm} \\
\mathrm{Re}=50-4000\end{array}$ & $\begin{array}{l}\text { Measured Nusselt numbers lower than } \\
\text { correlation for laminar flow; higher for } \\
\text { turbulent flow although trend correctly } \\
\text { captured by correlation. }\end{array}$ & $\begin{array}{l}\text { Laminar flow }(\operatorname{Re}<2200) \text { : Eq. }(4) \\
\text { Fully developed turbulent flow }(\operatorname{Re}> \\
\text { 10000): Eq. }(10)\end{array}$ & $\begin{array}{l}\text { Laminar flow } \\
N u=0.1165(D / P)^{0.81}(b / w)^{-0.79} \operatorname{Re}^{0.62} \operatorname{Pr}^{0.33} \\
(17) \\
\text { Turbulent flow } \\
N u=0.072(D / P)^{1.15}\left[1-2.421(Z-0.5)^{2}\right] \operatorname{Re}^{0.8} \operatorname{Pr}^{0.33} \\
(18)\end{array}$ \\
\hline Adams et al. [15] & $\begin{array}{l}D=760 \mu \mathrm{m} \\
L=63.5 \mathrm{~mm} \\
R e=2600-23000\end{array}$ & $\begin{array}{l}\text { Measured Nusselt numbers higher than } \\
\text { correlation for turbulent flow. }\end{array}$ & Turbulent flow: Eq. (12) & $\begin{array}{l}\text { Turbulent flow } \\
N u=N u_{G n}(1+F) \\
\text { where }_{F}=C \operatorname{Re}\left[1-\left(D / D_{0}\right)^{2}\right] \\
C=7.6 \times 10^{-6}, D_{0}=1.164 \mathrm{~mm} \\
f=\frac{1}{(1.82 \log (\operatorname{Re})-1.64)^{2}}\end{array}$ \\
\hline $\begin{array}{l}\text { Ravigururajan and } \\
\text { Drost [33] }\end{array}$ & $\begin{array}{l}w=270 \mu \mathrm{m} \\
b=1000 \mu \mathrm{m} \\
L=20.5 \mathrm{~mm} \\
R e=120-1300\end{array}$ & $\begin{array}{l}\text { Measured heat transfer coefficients higher } \\
\text { than laminar prediction. }\end{array}$ & $\begin{array}{l}\text { Laminar flow }(\operatorname{Re}<1400) \text { : Eq. (20) and } \\
\text { Choi et al. correlation, Eq. (14) }\end{array}$ & (क्ष \\
\hline Harms et al. [13] & $\begin{array}{l}w=251 \mu \mathrm{m} \\
b=1000 \mu \mathrm{m} \\
L=25 \mathrm{~mm} \\
\operatorname{Re}=173-12900\end{array}$ & $\begin{array}{l}\text { Measured local Nusselt numbers in good } \\
\text { agreement with laminar prediction }\end{array}$ & $\begin{array}{l}\text { Laminar developing flow }(\operatorname{Re}<1500) \text { : } \\
\text { Shah and London [27] }\end{array}$ & - \\
\hline
\end{tabular}




\begin{tabular}{|c|c|c|c|c|c|}
\hline Reference & Parameters & $\begin{array}{c}\text { Conclusions on Validity of } \\
\text { Conventional Theory }\end{array}$ & $\begin{array}{c}\text { Conventional Correlations used in } \\
\text { Comparisons }\end{array}$ & \multicolumn{2}{|c|}{ Proposed New Correlation } \\
\hline Qu et al. [34] & $\begin{array}{l}D_{h}=62-169 \mu \mathrm{m} \\
\operatorname{Re}<1400\end{array}$ & $\begin{array}{l}\text { Nusselt numbers lower than CFD } \\
\text { prediction. }\end{array}$ & $\begin{array}{l}\text { Numerical solution of laminar Navier- } \\
\text { Stokes equations. }\end{array}$ & $N u=N u_{\text {theory }}$ & $\left(\frac{\mu_{R m}}{\mu_{R m W}}\right)$ \\
\hline Popescu et al. [12] & $\begin{array}{l}\mathrm{w}=128-521 \mu \mathrm{m} \\
\mathrm{b}=10 \mathrm{~mm} \\
\mathrm{Re}=300-900\end{array}$ & $\begin{array}{l}\text { Nusselt numbers match numerical } \\
\text { predictions for } 263 \mu \mathrm{m}, 521 \mu \mathrm{m} \text { channels, } \\
\text { but lower than predictions for } 128 \mu \mathrm{m} \\
\text { channel. }\end{array}$ & $\begin{array}{l}\text { Numerical solution of laminar Navier- } \\
\text { Stokes equations. }\end{array}$ & & - \\
\hline $\begin{array}{l}\text { Qu and Mudawar } \\
\text { [14] }\end{array}$ & $\begin{array}{l}\mathrm{w}=231 \mu \mathrm{m} \\
\mathrm{b}=713 \mu \mathrm{m} \\
\mathrm{L}=44.8 \mathrm{~mm} \\
\mathrm{Re}=139-1672\end{array}$ & $\begin{array}{l}\text { Measured temperature distribution well } \\
\text { predicted by CFD prediction. }\end{array}$ & $\begin{array}{l}\text { Numerical solution of laminar Navier- } \\
\text { Stokes equations. }\end{array}$ & & - \\
\hline Celata et al. [35] & $\begin{array}{l}D=130-290 \mu \mathrm{m} \\
L=90 \mathrm{~mm} \\
R e=100-6000\end{array}$ & $\begin{array}{l}\text { Measured Nusselt numbers not } \\
\text { adequately predicted by correlations for } \\
\text { laminar and turbulent flows. }\end{array}$ & $\begin{array}{l}\text { Laminar flow: Eq. (7) } \\
\text { Fully developed turbulent flow: } \\
\text { Eqs. (10) and (12) }\end{array}$ & & - \\
\hline Bucci et al. [36] & $\begin{array}{l}D=172-520 \mu \mathrm{m} \\
L=26,70 \mathrm{~mm} \\
R e=100-6000\end{array}$ & $\begin{array}{l}\text { Measured Nusselt numbers higher than } \\
\text { correlation for both laminar and turbulent } \\
\text { flows; smallest microtube results match } \\
\text { Adams correlation, Eq. (19) for turbulent } \\
\text { flow. }\end{array}$ & $\begin{array}{l}\text { Laminar flow: Eq. (7) } \\
\text { Turbulent flow: Eqs. (10), (11) and (19) }\end{array}$ & & - \\
\hline $\begin{array}{l}\text { Owhaib and Palm } \\
\text { [37] }\end{array}$ & $\begin{array}{l}\mathrm{D}=0.8-1.7 \mathrm{~mm} \\
L=325 \mathrm{~mm} \\
\mathrm{Re}=1000-17000\end{array}$ & $\begin{array}{l}\text { Measured Nusselt numbers in good } \\
\text { agreement with correlation for laminar } \\
\text { flow, but not for turbulent flow. }\end{array}$ & $\begin{array}{l}\text { Laminar flow: Eq. (4) } \\
\text { Turbulent flow: Eqs. (10), (11) and (12). }\end{array}$ & & - \\
\hline
\end{tabular}


Table 5. Assessment of entrance lengths in experimental studies of microchannels.

\begin{tabular}{|c|c|c|c|c|c|c|c|c|c|c|}
\hline $\begin{array}{c}\mathbf{D}_{\mathbf{h}} \\
(\boldsymbol{\mu m})\end{array}$ & $\begin{array}{c}\mathbf{L} \\
(\mathbf{m m})\end{array}$ & $\mathbf{R} \mathbf{e}^{\S}$ & $\begin{array}{c}\text { Working } \\
\text { fluid }\end{array}$ & $\begin{array}{c}\text { Fluid } \\
\text { temperature } \\
\text { range } \\
\left({ }^{\circ} \mathbf{C}\right)\end{array}$ & $\mathbf{P r}$ & $\mathbf{X}+$ & $\mathbf{L}_{\text {ent,hyd } / \mathbf{L}}^{*}$ & $\mathbf{x}^{*}$ & $\mathbf{L}_{\text {ent, }, \mathbf{L}}$ & Reference \\
\hline 158 & 30 & 1200 & Nitrogen & $-110 \sim 25$ & 0.716 & 0.148 & 0.34 & 0.207 & 0.24 & Wu and Little [29] \\
\hline 81 & 52 & 1000 & $\begin{array}{c}\text { Nitrogen } \\
\text { (gas) }\end{array}$ & 60 & 0.713 & 0.640 & 0.08 & 0.898 & 0.06 & Choi et al. [1] \\
\hline 435 & 46 & 1150 & Water & - & 5.5 & 0.092 & 0.54 & 0.017 & 2.99 & Rahman and Gui [30] \\
\hline 343 & 50 & 1000 & Water & $22 \sim 40$ & 5.8 & 0.146 & 0.34 & 0.025 & 1.99 & Peng et al. [32] \\
\hline 425 & 20.5 & 700 & R124 & 24 & 4.68 & 0.069 & 0.73 & 0.015 & 3.39 & Ravigururajan and Drost [33] \\
\hline 403 & 25 & 800 & Water & $20 \sim 33$ & 5.8 & 0.077 & 0.65 & 0.013 & 3.75 & Harms et al. [13] \\
\hline 349 & 44.8 & 700 & Water & $15 \sim 75$ & 5.0 & 0.183 & 0.27 & 0.037 & 1.36 & Qu and Mudawar [34] \\
\hline 130 & 90 & 1000 & Water & - & 5.5 & 0.310 & 0.16 & 0.056 & 0.89 & Celata et al. [35] \\
\hline 520 & 70 & 1100 & Water & - & 5.5 & 0.122 & 0.41 & 0.022 & 2.25 & Bucci et al. [36] \\
\hline 800 & 325 & 1500 & R134a & - & 4.8 & 0.271 & 0.19 & 0.056 & 0.89 & Owhaib and Palm [37] \\
\hline 318 & 25.4 & 300 & Water & $22 \sim 70$ & 5.0 & 0.266 & 0.19 & 0.053 & 0.94 & Present work \\
\hline 318 & 25.4 & 1500 & Water & $22 \sim 70$ & 5.0 & 0.053 & 0.94 & 0.011 & 4.55 & Present work \\
\hline 534 & 25.4 & 300 & Water & $22 \sim 70$ & 5.0 & 0.0938 & 0.53 & 0.019 & 2.63 & Present work \\
\hline 534 & 25.4 & 1800 & Water & $22 \sim 70$ & 5.0 & 0.0156 & 3.20 & 0.003 & 17.59 & Present work \\
\hline
\end{tabular}

${ }^{\S}$ Except for the present work, entrance lengths are determined for the average laminar Reynolds number value in each study.

*Hydrodynamic developing lengths are calculated by assuming uniform inlet velocity. 
Table 6. Difference between experimental results and numerical predictions (for $\mathrm{H} 1$, thermally developing conditions).

\begin{tabular}{|c|c|c|c|}
\hline Test \# & $\mathbf{w}(\boldsymbol{\mu m})$ & Deviation from $[\mathbf{2 1}]^{*}(\%)$ & $\begin{array}{c}\text { Deviation from present numerical } \\
\text { predictions (thin wall model) }\end{array}$ \\
\hline 1 & 194 & $3.4 \pm 2.1$ & $6.5 \pm 3.5$ \\
\hline 2 & 229 & $8.1 \pm 5.6$ & $4.7 \pm 3.1$ \\
\hline 3 & 300 & $6.1 \pm 4.9$ & $4.5 \pm 3.4$ \\
\hline 4 & 339 & $4.4 \pm 3.6$ & $7.7 \pm 3.7$ \\
\hline 5 & 534 & $5.5 \pm 3.0$ & $2.4 \pm 1.5$ \\
\hline \multicolumn{2}{|c|}{ Mean } & $5.5 \pm 1.8$ & $5.2 \pm 2.0$ \\
\hline
\end{tabular}

*Based on results for $\mathrm{Re}<1500$ 


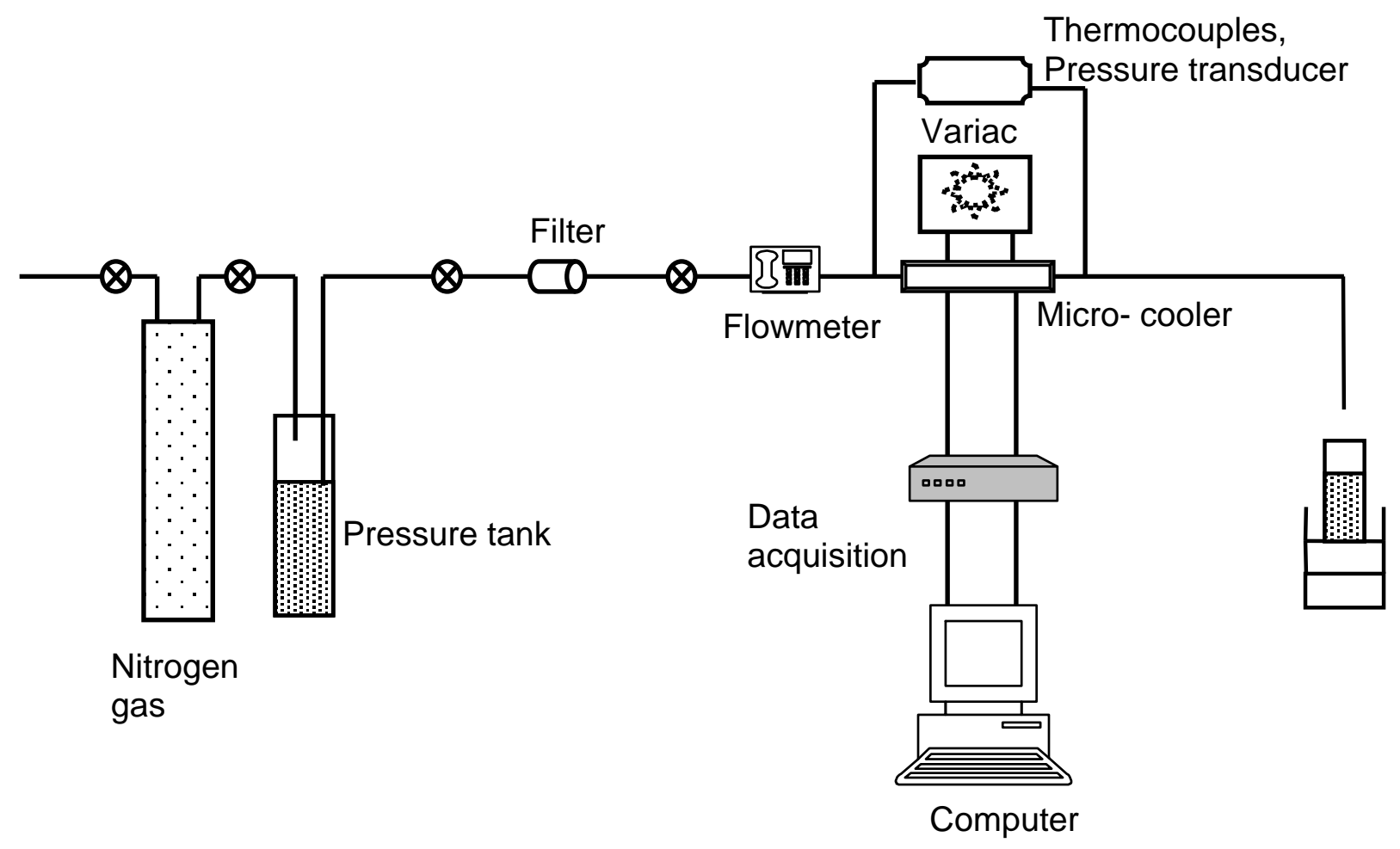

Fig. 1. Schematic of the experimental apparatus. 


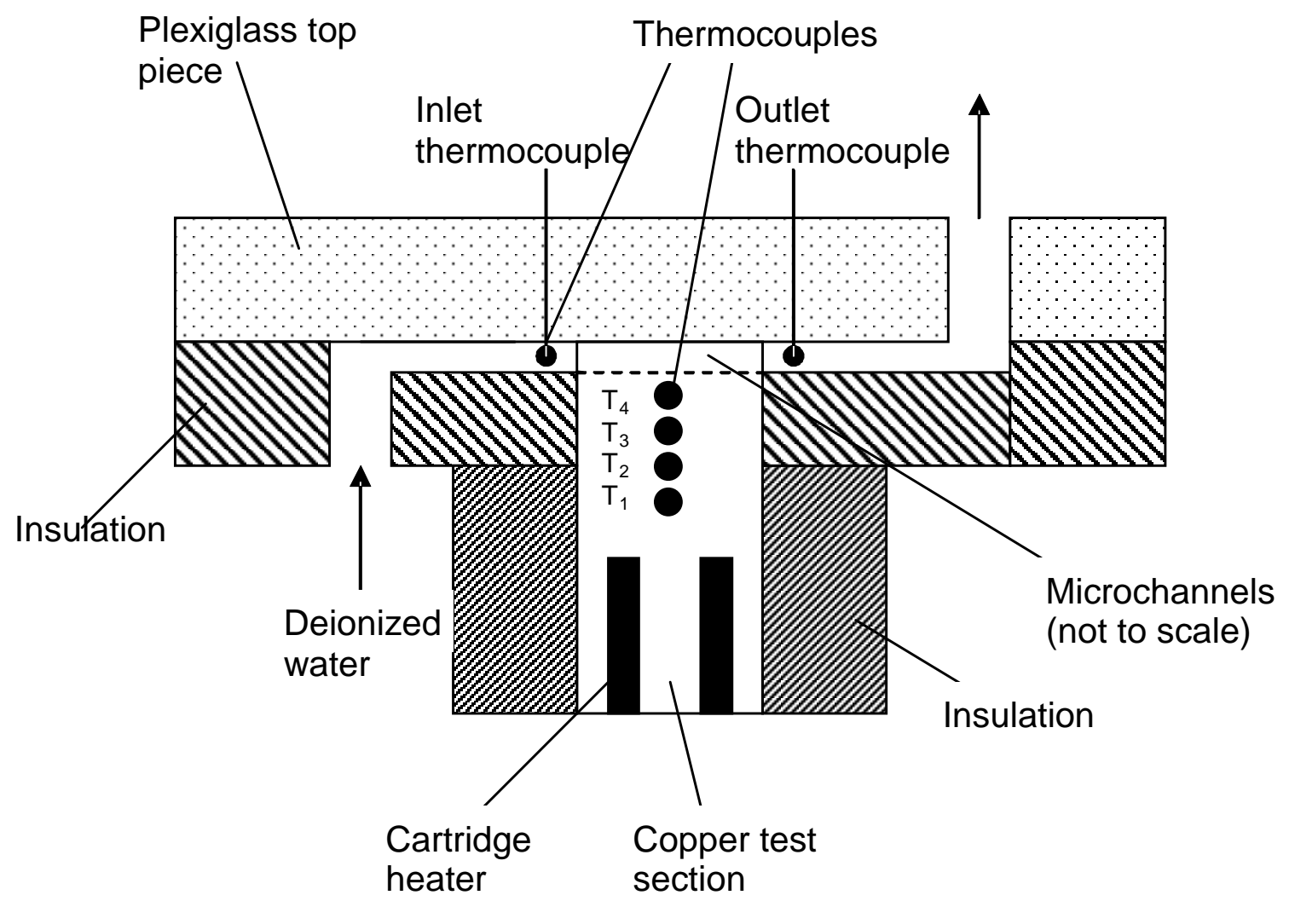

(a)

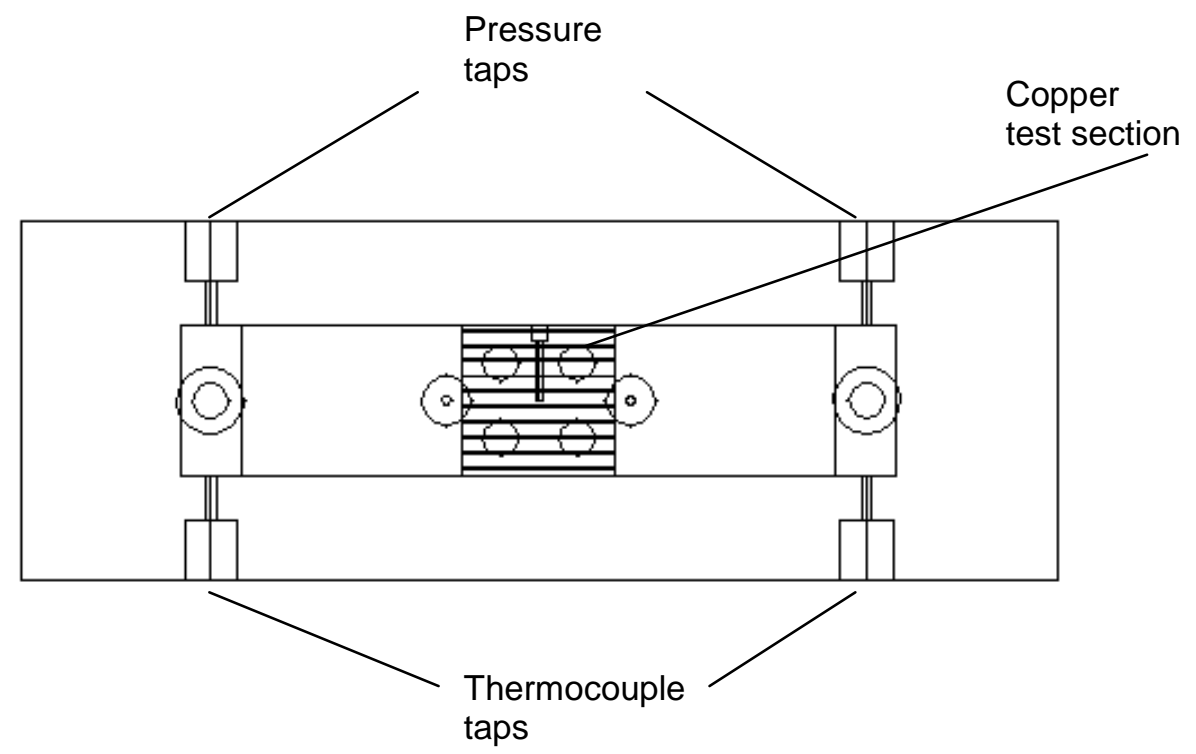

(b)

Fig. 2. Detailed view of the test section: (a) Side view (not to scale), and (b) Top view (to scale). 


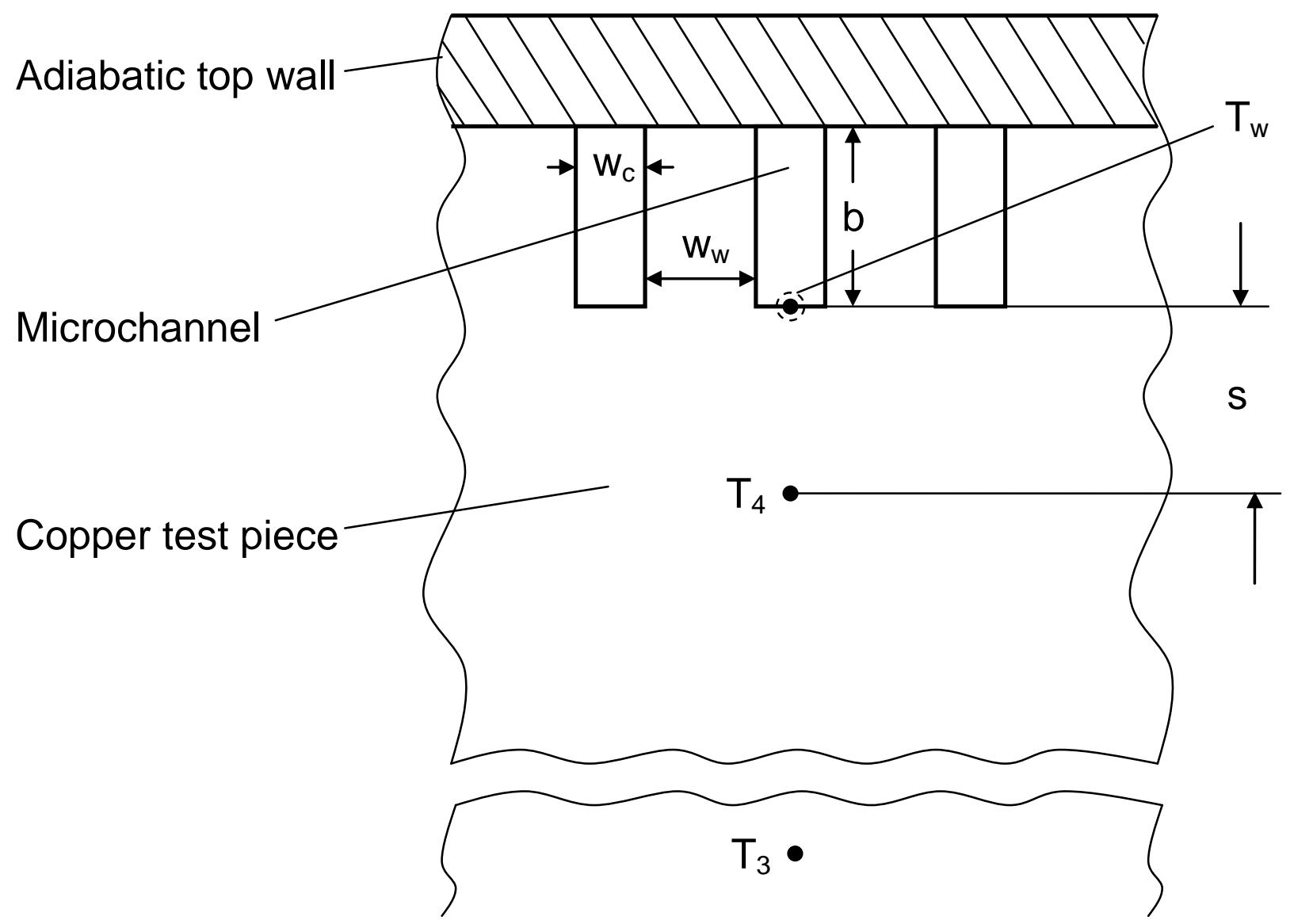

Fig. 3. Cross section of the microchannel test piece (not to scale). 


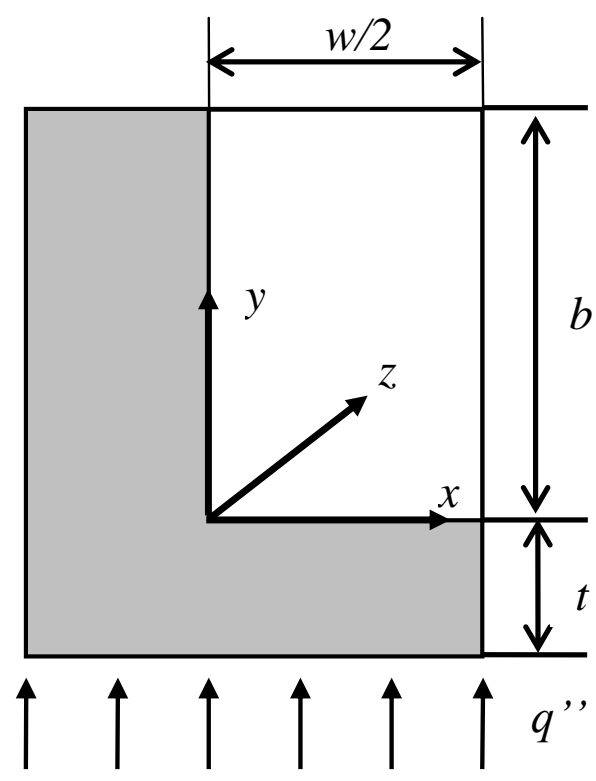

(a)

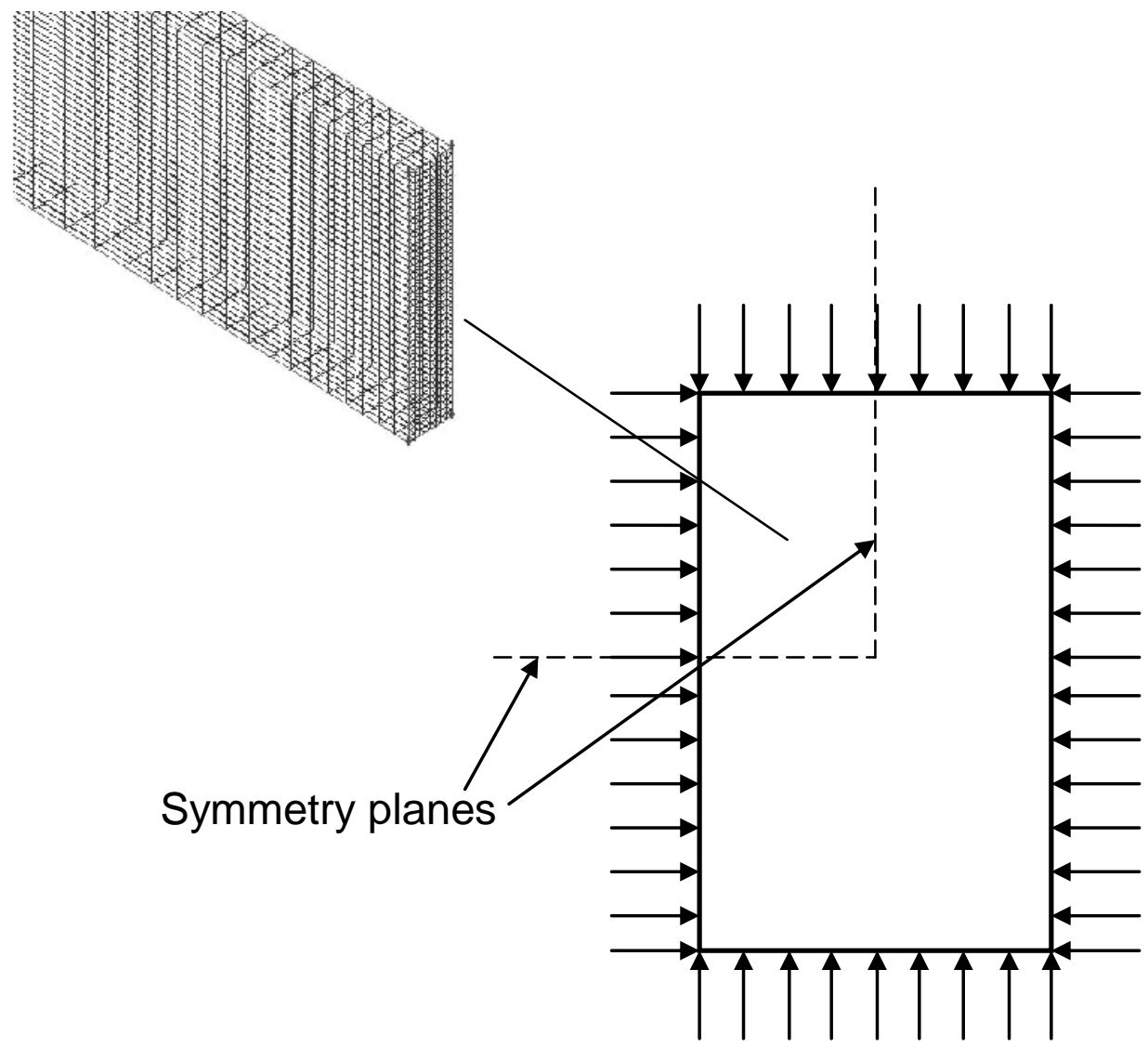

(b)

Fig. 4. Microchannel domains considered for (a) comprehensive 3-D conjugate analysis, and (b) simplified analyses. 


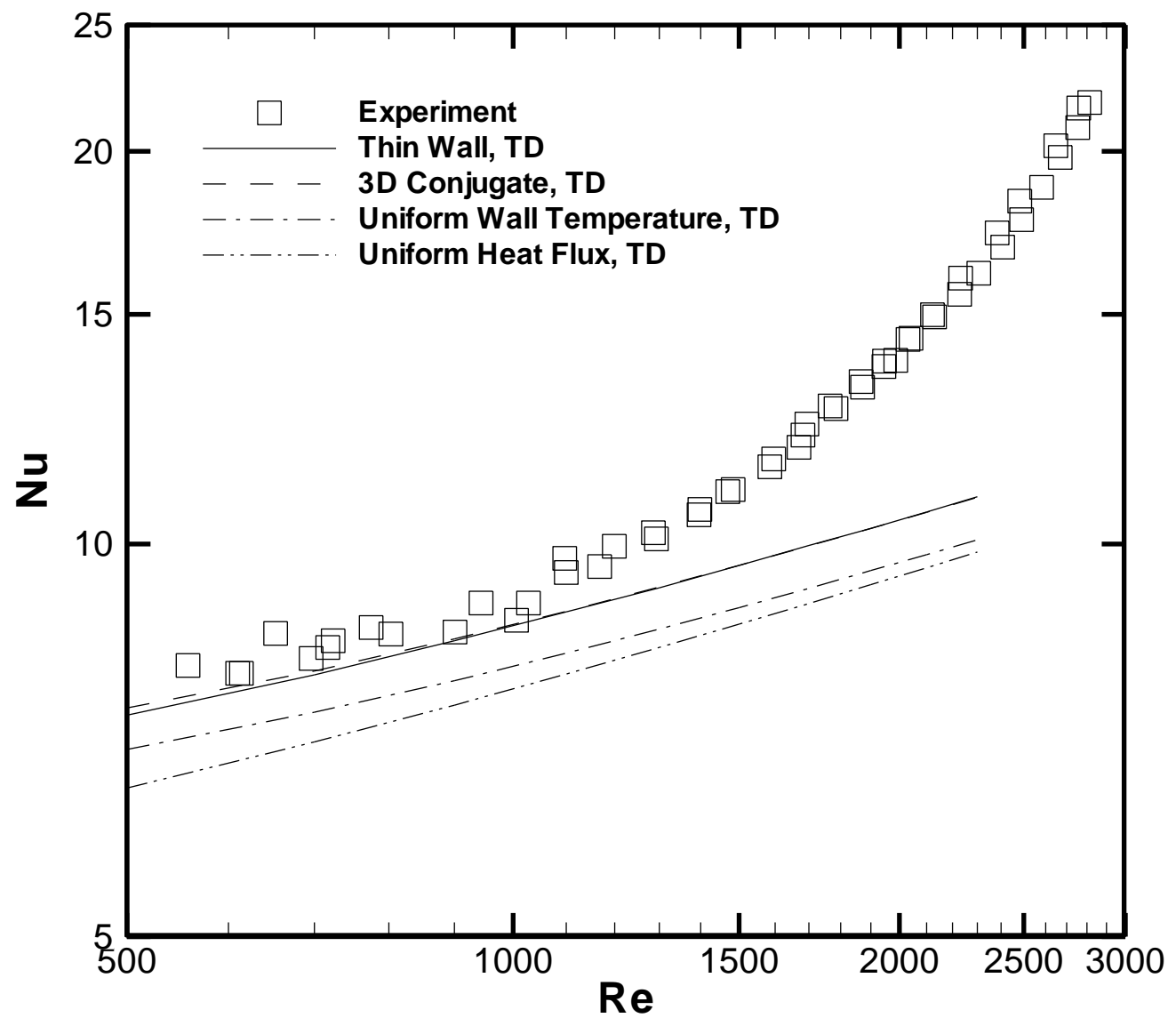

Fig. 5. Comparison of the average Nusselt numbers obtained from different numerical analyses for the $194 \mu \mathrm{m}$ wide microchannels. 


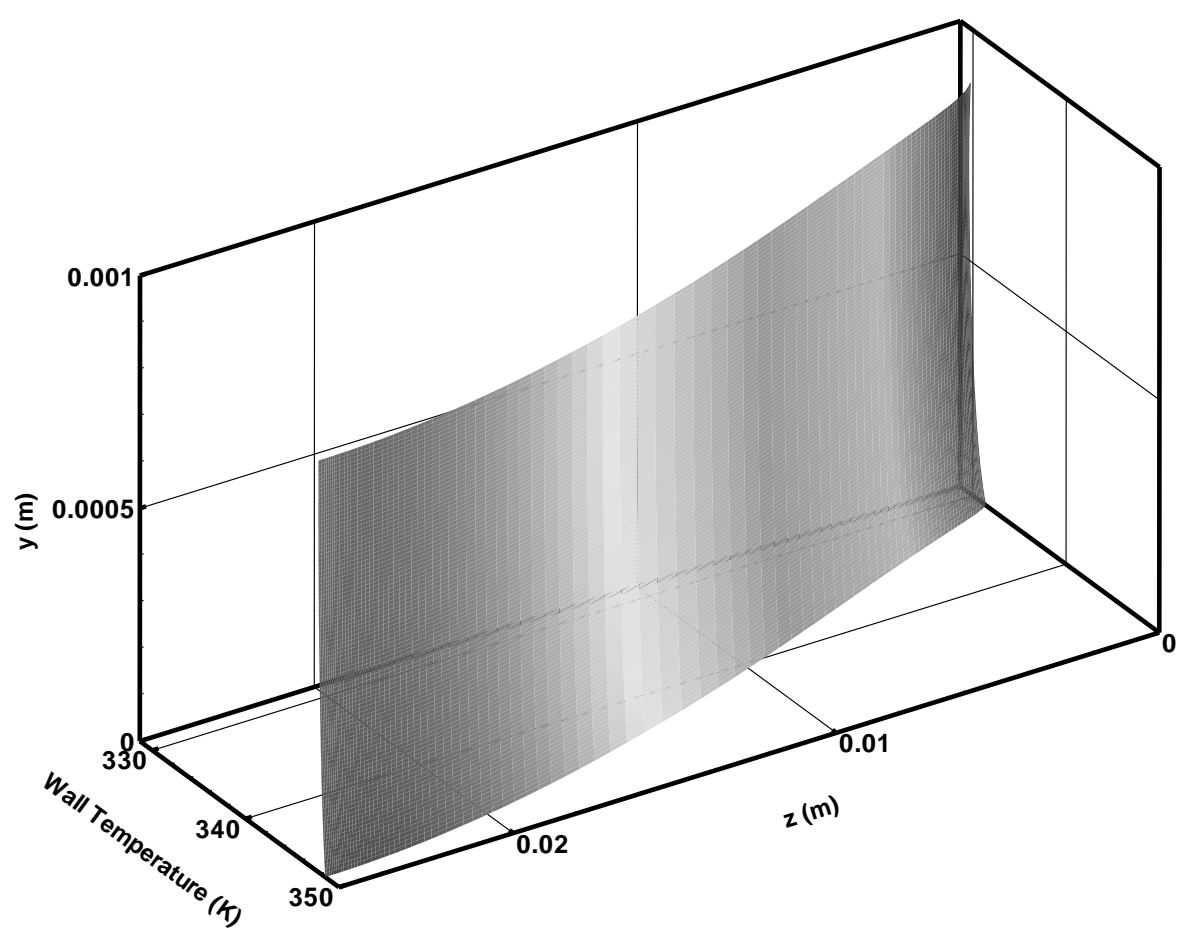

(a)

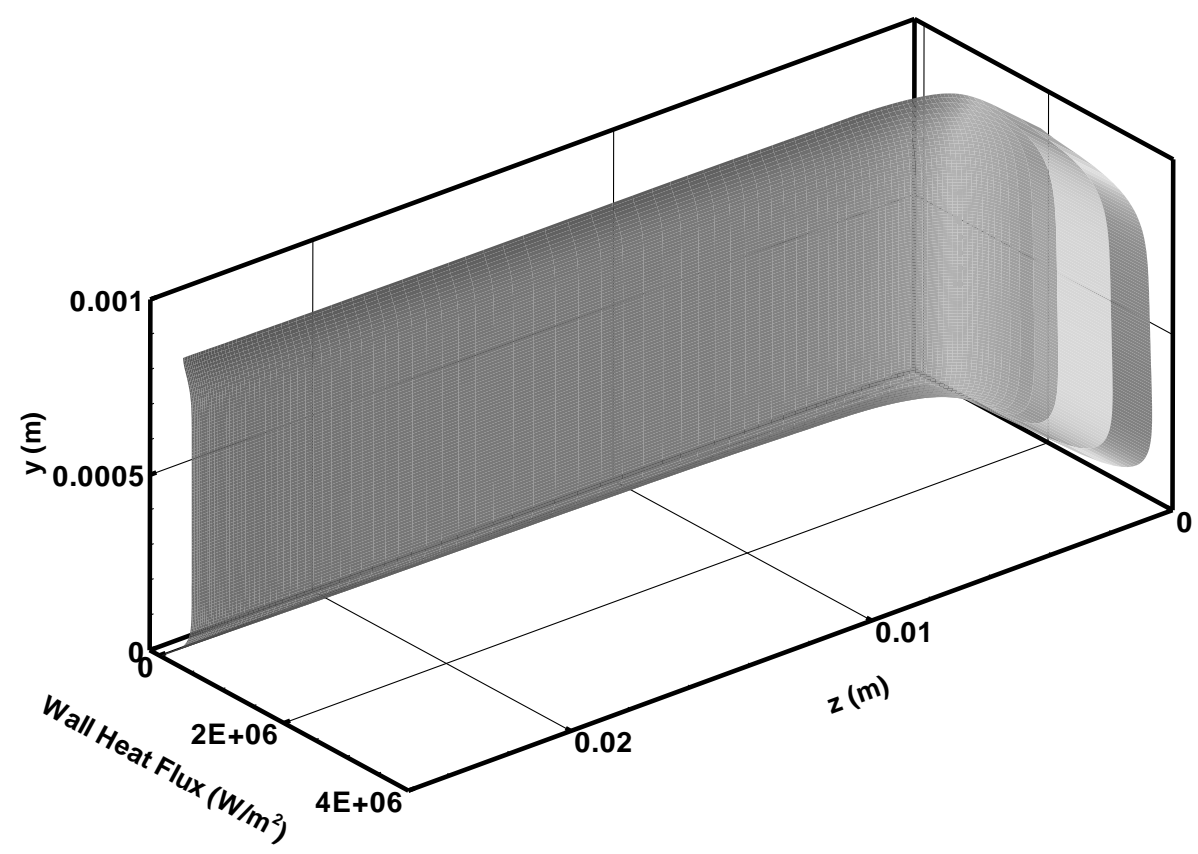

(b)

Fig. 6. Local profiles of (a) temperature and (b) heat flux on the channel side wall for the $194 \mu \mathrm{m}$ wide microchannels at a Reynolds number of 1100 . 


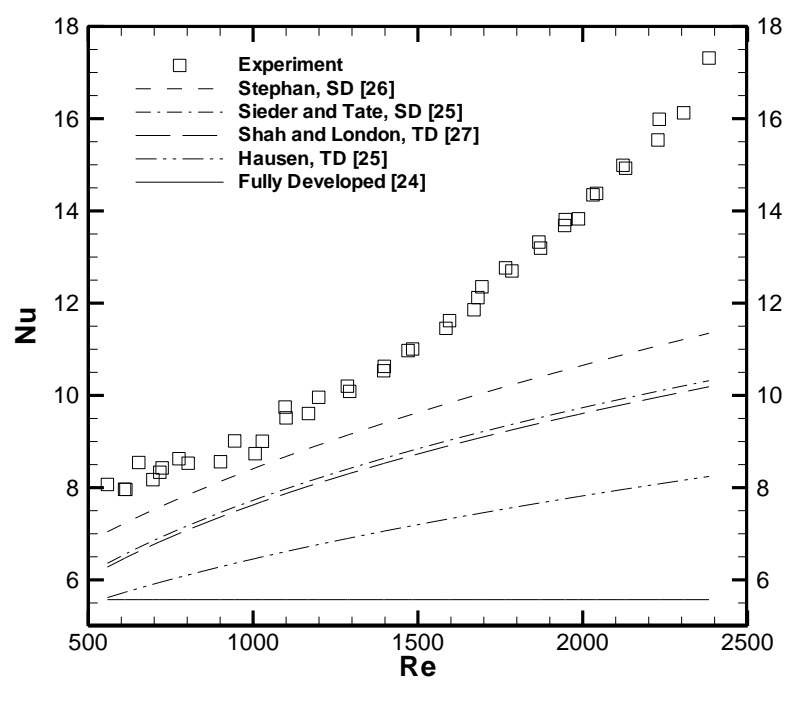

(a)

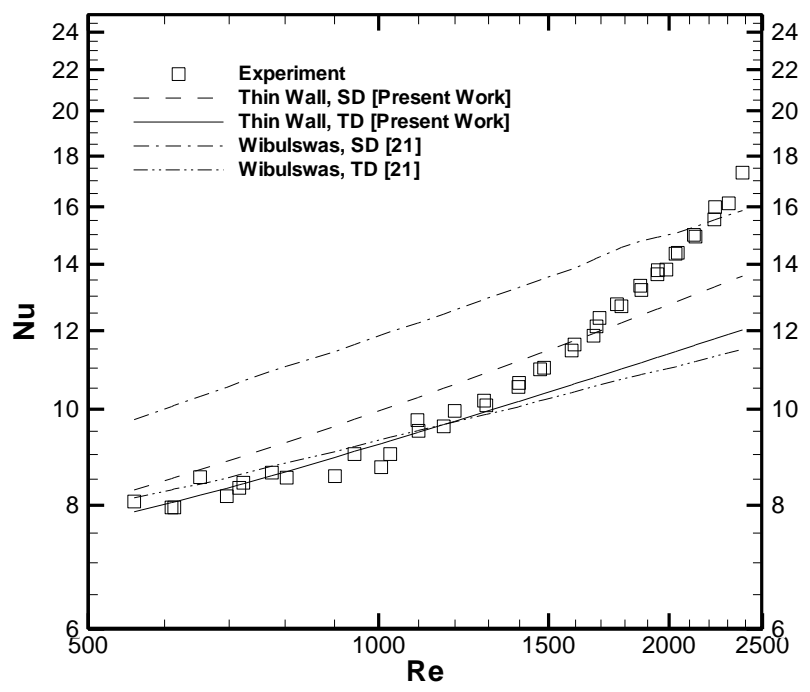

(b)

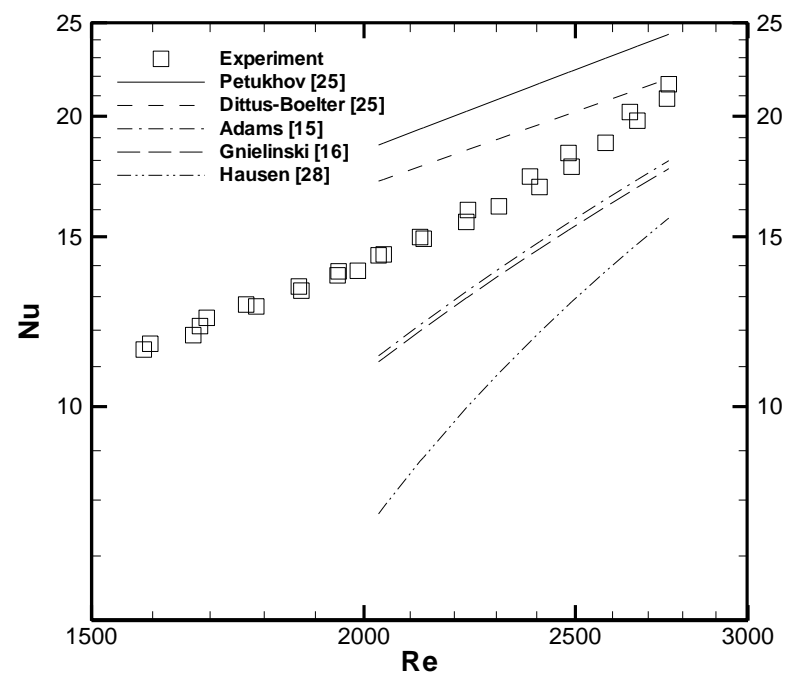

(c)

Fig. 7. Nusselt numbers for the $194 \mu \mathrm{m}$ wide microchannels. Experimental data compared against: (a) correlations for laminar flow (SD - simultaneously developing, TD - thermally developing); (b) numerical predictions for laminar flow; and (c) correlations for turbulent flow. 


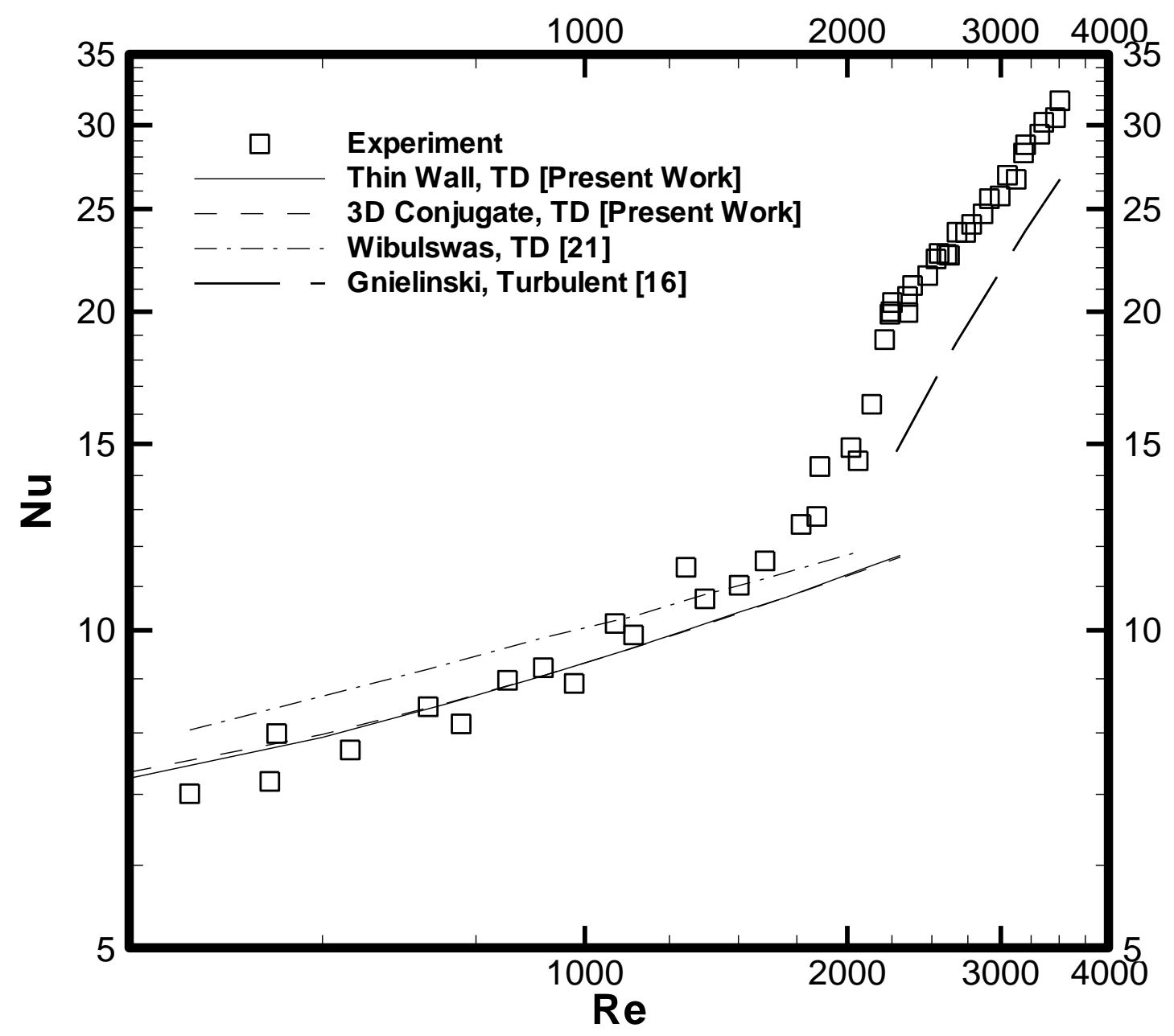

Figure 8. Nusselt numbers for the $229 \mu \mathrm{m}$ wide microchannels. 


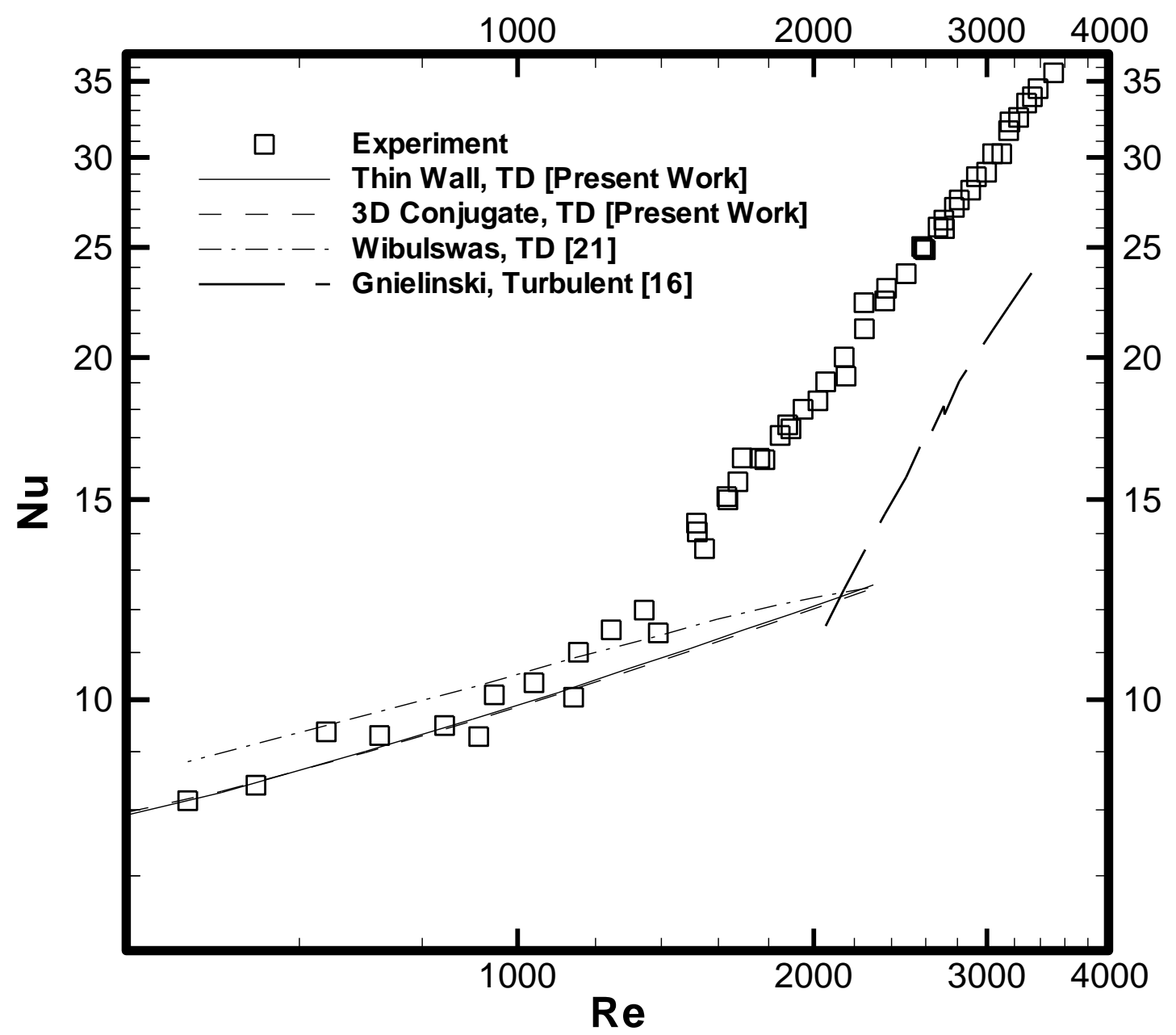

Figure 9. Nusselt numbers for the $300 \mu \mathrm{m}$ wide microchannels. 


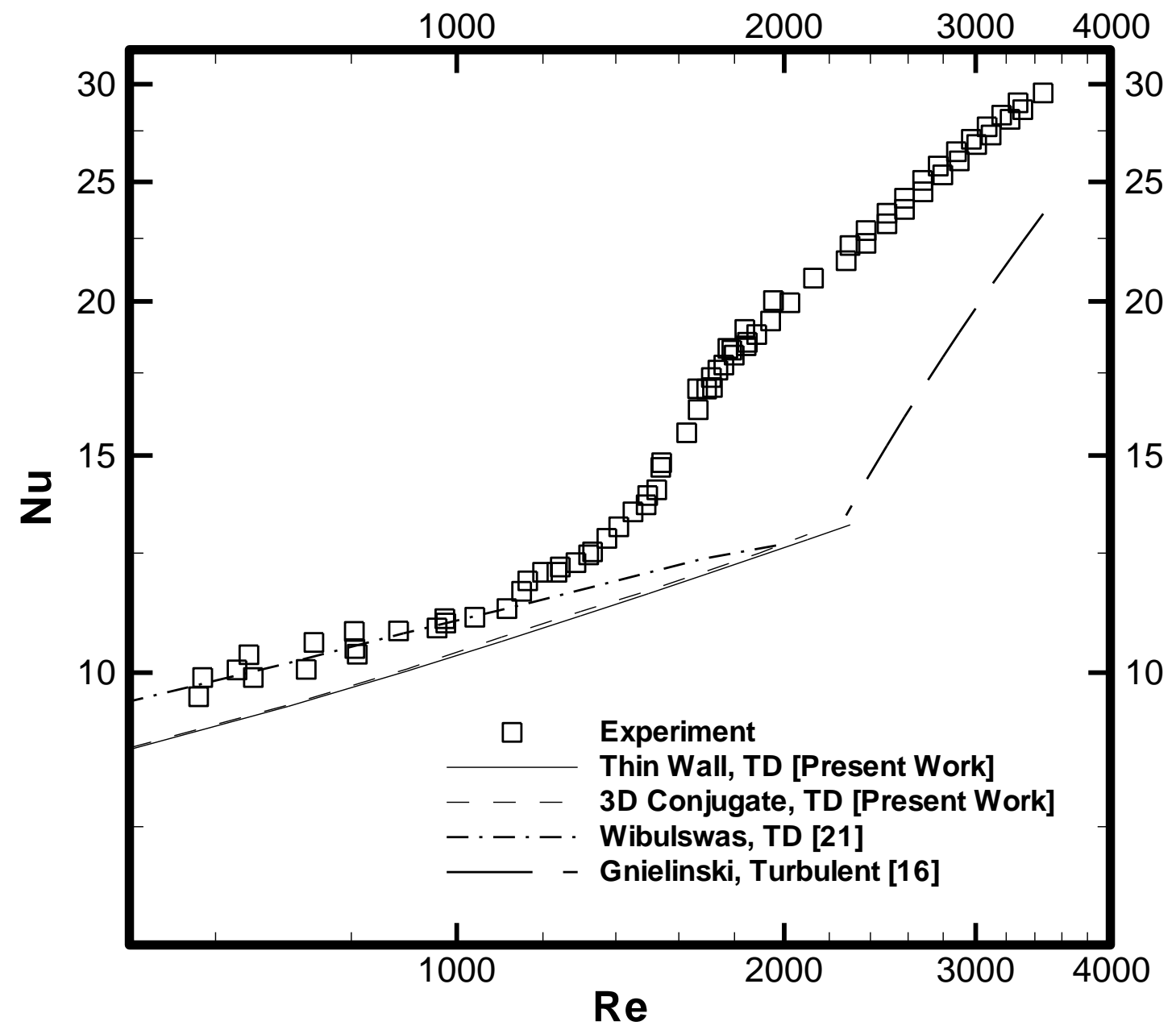

Figure 10. Nusselt numbers for the $339 \mu \mathrm{m}$ wide microchannels. 


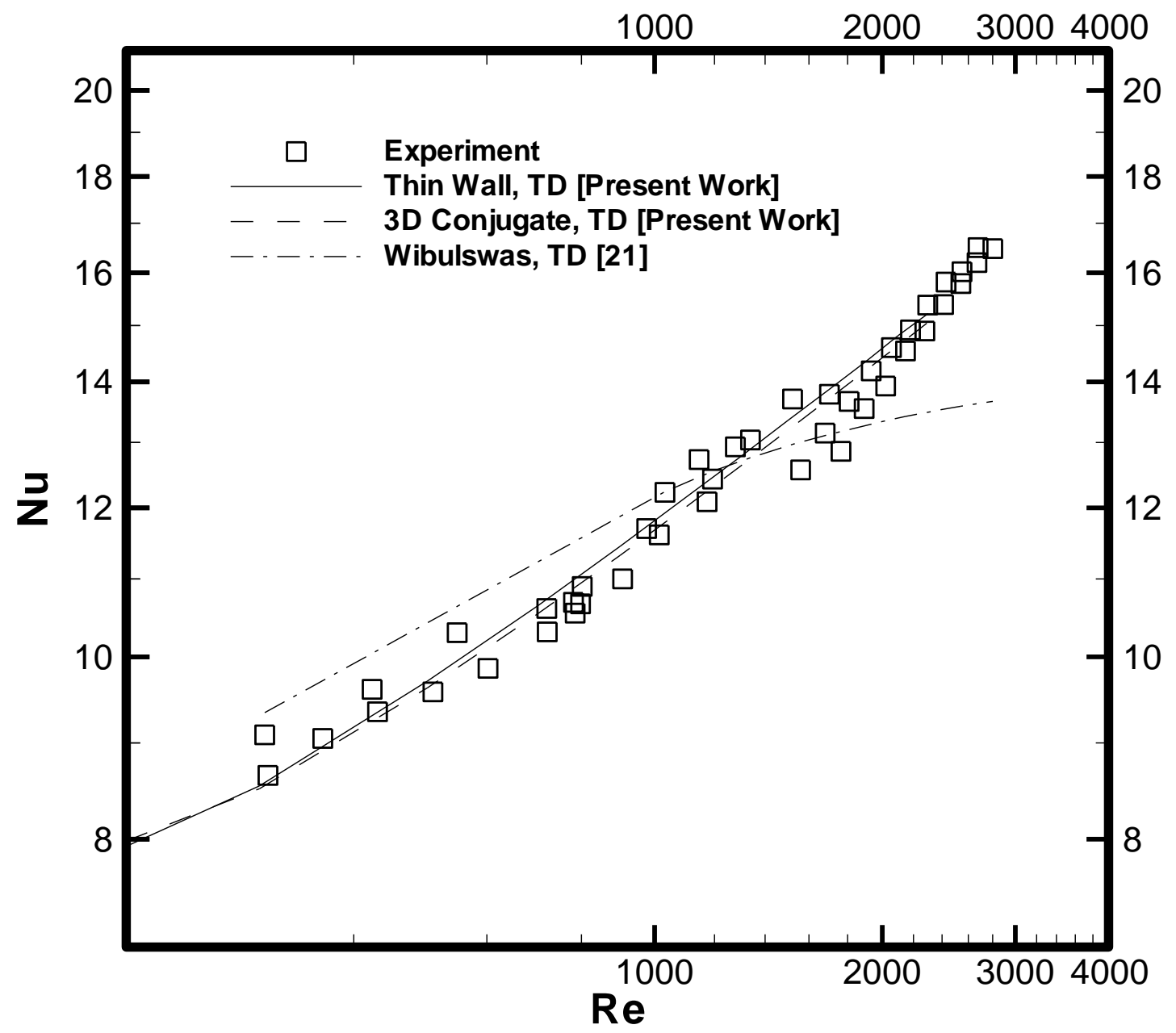

Figure 11. Nusselt numbers for the $534 \mu \mathrm{m}$ wide microchannels. 


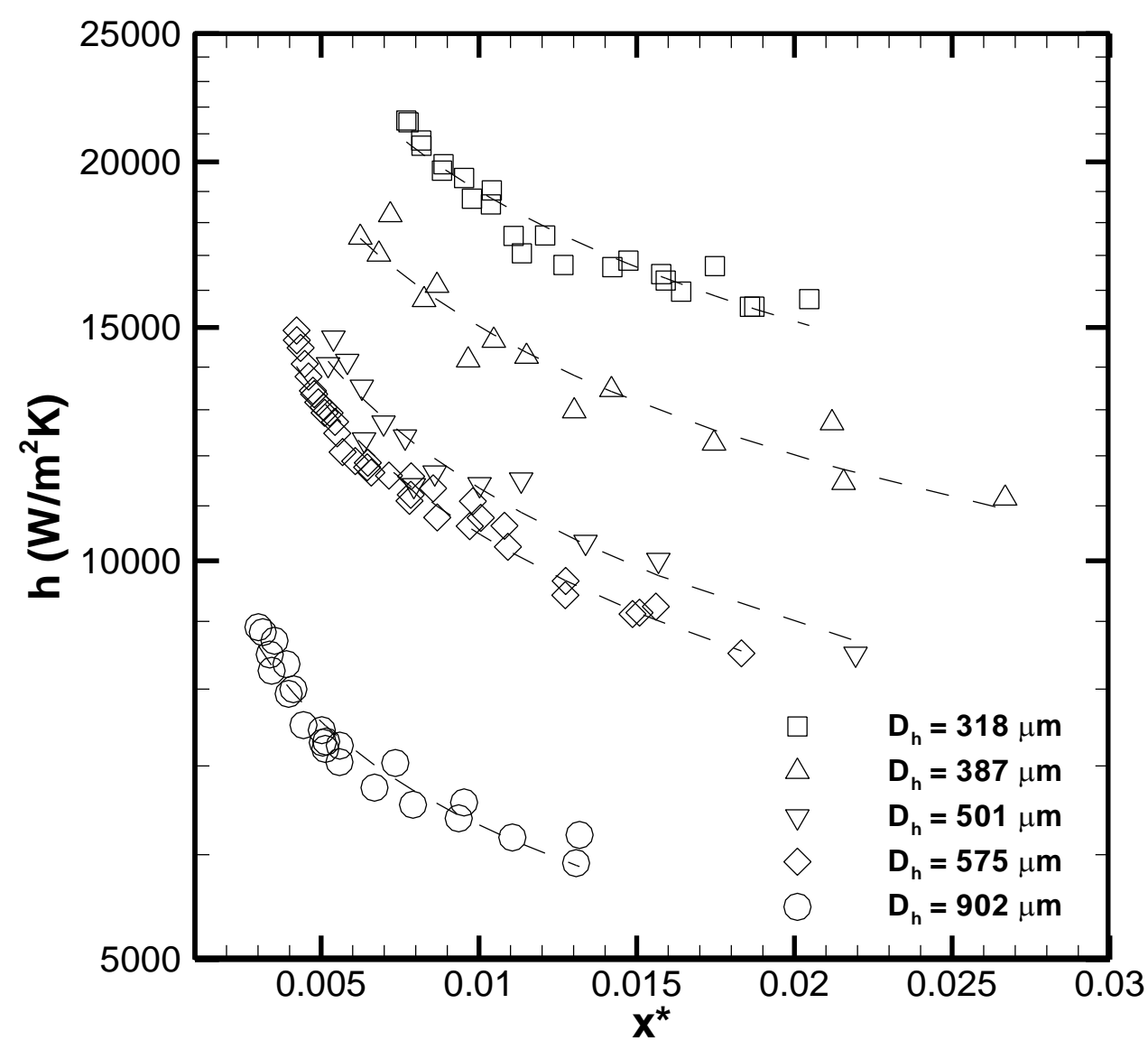

Fig. 12. Dependence of heat transfer coefficient on Reynolds numbers (in terms of dimensionless thermal axial distance $x^{*}$ ) for channels of different hydraulic diameters. The dashed lines are trend line fits to the experimental data. 